\title{
The syntax of semantic agreement in English ${ }^{1}$
}

\author{
PETER W. SMITH \\ Goethe-Universität, Frankfurt
}

(Received 25 November 2013; revised 24 October 2016)

\begin{abstract}
This paper investigates the properties of plural agreement that is triggered by collective nouns in British English. Both singular and plural agreement are able to appear with these collective nouns, which are shown to be morphologically singular but semantically plural. Plural agreement, however, is systematically more restricted than singular agreement, appearing in a subset of the environments where singular agreement is allowed. Restrictions on plural come from the nature of agreement; semantic agreement features can only enter into agreement when the controller of agreement c-commands the target of agreement, whereas morphologically motivated agreement is not subject to the same structural restriction. This asymmetry between the two types of agreement is shown to arise from the proposal that AGREE (Chomsky 2000, 2001) is distributed over the syntactic and post-syntactic components (Arregi \& Nevins 2012).
\end{abstract}

KEYWORDS: agreement, features, Agree, semantic agreement

\section{INTRODUCTION}

In English, nouns that are morphologically singular, but denote collections, such as committee, government, team, etc., are allowed to control both the expected singular agreement on the verb and also plural agreement. The availability of plural agreement differs across dialects, with British dialects showing higher frequency of plural agreement than American dialects; however, the possibility of plural agreement is attested in various dialects (see Quirk et al. 1985, Levin 2001, Huddleston \& Pullum 2002, Hristov 2013 and below for discussion). For instance, in the following examples, all sentences are grammatical in English, though the extent to which speakers will accept (1b) and (1d) varies across dialects. Throughout this paper, I focus mostly on British English, as it is the dialect where plural agreement is most readily found (Levin 2001).

[1] I would like to thank Bob Borsley for much helpful advice with this paper, as well as three anonymous reviewers for Journal of Linguistics. For discussions and comments on the material here, I would like to thank Scott AnderBois, Karlos Arregi, Jon Gajewski, Katharina Hartmann, Johannes Mursell, Andrew Nevins, Hazel Pearson as well as audiences at GoetheUniversität Frankfurt, the University of Connecticut, ConSOLE XX (Universität Leipzig) and ECO5 (UMass Amherst). I would like to thank, in particular, Jonathan Bobaljik, Željko Bošković, Beata Moskal and Susanne Wurmbrand, all of whom provided extensive discussion and comments on various versions of this paper. All errors are naturally my own responsibility. 
(1) (a) The government has approved the measure.

(b) The government have approved the measure.

(c) The committee decides who is hired.

(d) The committee decide who is hired.

Far from being a quirk of verbal agreement, the alternation between singular and plural agreement is quite systematic across agreement targets. As shown below, the alternation is seen on both anaphors (2a,b) and pronouns $(2 \mathrm{c}, \mathrm{d})$.

(2) (a) That team nominated each other for Player of the Year awards.

(b) The government gave itself a deadline of September for passing legislation.

(c) This government is corrupt. They are nothing but crooks.

(d) The committee is not making decisions right now. It will meet again next quarter.

What is interesting about this construction is not only the fact that an item that is morphologically singular is able to control plural agreement on the verb, but also the fact that the choice between singular and plural agreement is not without restrictions. Corbett (1979), citing originally Perlmutter (1972), notes that plural agreement controlled by collective nouns (CNPs henceforth) is restricted by syntactic context. While the verb can be either plural or singular, demonstratives will only show singular agreement, (3), and, as Elbourne (1999) notes, this is the case even when plural agreement is controlled elsewhere, (4). ${ }^{2}$

(3) (a) This committee sat late in order to make a decision.

(b) *These committee sat late in order to make a decision.

(4) (a) This committee are deciding on a solution.

(b) *These committee are deciding on a solution.

Contrasting (3) and (4) with (1) and (2), we see that demonstratives seem to show deviant behaviour with respect to agreement. The general pattern seems to be that elements that are sensitive to number agreement are freely able to be either singular or plural when occurring with a CNP, yet demonstratives for some reason take only singular agreement.

In addition to the restrictions seen with plural agreement on demonstratives, there are three other discrepancies between singular and plural agreement controlled by CNPs. First, as noted in Elbourne (1999) and Munn (1999), existential constructions in English do not allow for plural agreement when the associate argument is a CNP, (5). This is surprising, since plural agreement is normally

[2] Throughout this article, I cite Elbourne (1999) for Elbourne's data and relevant analysis. However, Elbourne (1999) is published as part of a larger paper in Sauerland \& Elbourne (2002), and largely the same arguments and data can be found there also. 
able to be triggered by plural associates in existential constructions in English, as shown in (6).

(5) (a) There is a committee deciding the budget for next year.

(b) *There are a committee deciding the budget for next year.

(6) There are three dogs in the garden.

Another discrepancy noted by Elbourne is the reconstruction potential for a CNP when it controls plural agreement versus singular agreement. Specifically, Elbourne notes that if a raised CNP controls singular agreement in the matrix clause, it is able to reconstruct into the infinitival clause for interpretation, (7a), whereas if plural agreement is controlled as in (7b), then reconstruction is impossible (examples from Elbourne 1999).

(7) (a) A northern team is likely to be in the final.

$\exists \gg$ likely / likely $\gg \exists$

(b) A northern team are likely to be in the final. $\exists \gg$ likely $/ *$ likely $\gg \exists$

In the above, the wide scope reading would pick out a specific northern team that is likely to be in the final, with the narrow scope reading something akin to it being likely that some northern team is likely to be in the final, but with no specific one.

A final asymmetry between singular and plural agreement triggered by CNPs is noted by den Dikken (2001), where he shows that in the following, (8a) is ambiguous between two readings in a way that (8b) is not. Specifically, (8a), with singular agreement, allows for both (what Den Dikken terms) the subject reading as well as the predicate reading, which are paraphrased in (9a) and (9b), respectively; (8b), on the other hand, differing minimally in only the number agreement, allows for only the subject reading. The subject reading notes that the best committee is the committee that belongs (in some way) to them, for instance they are in charge of it, without necessarily being a member of the committee. In the predicate reading, however, it is important that they are members of the best committee.

(8) (a) The best committee is theirs. committee $=\boldsymbol{V}$ subject $/ \boldsymbol{V}$ predicate

(b) The best committee are theirs. committee $=\boldsymbol{V}$ subject $/ \boldsymbol{X}$ predicate

(9) (a) The best committee belongs to them. (subject reading)

(b) The committee that they belong to is the best committee. (predicate reading)

A final aspect of CNP agreement in English is an interesting pattern of agreement mismatches. ${ }^{3}$ As shown above, in (4a), it can be the case that when there are two targets for agreement, their values can mismatch with respect to each

[3] This has to the best of my knowledge not previously been discussed in the literature, though Huddleston \& Pullum (2002: 495) note the pattern with possessive pronouns. 
other. In (4a), this is shown with a singular demonstrative and a plural auxiliary. Now, we know that demonstratives can only take singular agreement; thus, it could be supposed that the mismatch in (4a) is only allowed as there is no other option for the demonstrative. However, mismatches in agreement are allowed, as shown below in (10c), where the verbal agreement is singular and the anaphor agreement is plural. Both anaphor and verbal agreement can independently alternate between singular and plural; therefore, mismatches between targets are tolerated. Curiously, however, the converse mismatch is not allowed, as shown in (10d). Sentences with matching agreements are added for completeness, and are fully grammatical. ${ }^{4}$

(10) (a) The government has offered itself up for criticism (with this economic policy).

(b) The government have offered themselves / each other up for criticism.

(c) The government has offered ?themselves / each other up for criticism.

(d) *The government have offered itself up for criticism.

I do not offer an explanation for this pattern in this paper, as it would take us too far afield in an already long paper; however, I refer the reader to Smith (2015) and Smith (2016) for a full discussion of how to rule out the ungrammatical sentence within the framework that I oultine below in Section 3.

In summary, what needs to be explained about CNPs is the following: (i) how a morphologically singular noun can trigger plural agreement and (ii) why it is singular agreement that is available for all targets but plural is restricted. These two questions are interrelated and I will show that the answer follows from how the mechanism of AGREE (Chomsky 2000, 2001) treats semantically motivated agreement differently from morphologically motivated agreement in terms of structure.

The paper is organised as follows. In Section 2, I show that there is a structural generalisation that captures where singular agreement is allowed, but plural agreement is disallowed. In all the instances where plural agreement is disallowed, the CNP is structurally beneath the agreement target at the level of LF; that is, at LF, the agreement target c-commands, but is crucially not c-commanded by, the CNP. In Section 3, I discuss the implications of this, and show that it fundamental to understanding the restrictions on plural agreement, and that the analysis given here affords us a new perspective on first conjunct agreement in English existential constructions. In Section 4, I discuss previous approaches to

[4] Pollard \& Sag (1994) claim that sentences that have mismatched agreements are bad, so (10c) would be ungrammatical for them. I have checked this pattern with nine native speakers of dialects that allow for plural agreement to be controlled by CNPs, and it is uniformly agreed upon that (10c), while perhaps a little degraded for some speakers, is far better than (10d), which is strongly ungrammatical. 
the problems above, and show that while all offer partial solutions, none are able to provide a full account, while also suffering empirical problems. I briefly remark on cross-dialectal variation in Section 5 before concluding the paper in Section 6.

\section{A COMMON GENERALISATION}

My goal in this paper is to show that the restrictions on plural agreement with CNPs that were introduced above all stem from a structural restriction on semantically motivated agreement. I will begin by arguing for the following descriptive generalisation in (11), which for convenience I will term LF-Visibility. The goal of this section is to support the validity of the generalisation, before providing a theoretical account of it in Section 3. ${ }^{5}$

\section{LF-Visibility (descriptive generalisation)}

With CNPs, plural agreement requires the controller to c-command the target at LF, but singular agreement does not.

\subsection{Existential constructions}

Recall that with existential constructions, plural agreement is not able to be controlled by the CNP.

(12) (a) There is a committee deciding the budget for next year.

(b) *There are a committee deciding the budget for next year.

Existential constructions in English have attracted a wide variety of approaches in the literature (see Chomsky 1995, Lasnik 1995, Bošković 1997, Bobaljik 2002, Hazout 2004, Witkós 2004, among many others), and there exists no clear consensus on what approach is correct. I do not attempt to offer an analysis of the construction here, since it would take us too far from the topic at hand; however, one point that is pertinent to the discussion is the position that the associate DP holds in the structure. ${ }^{6}$ Some approaches take it that the associate at some point in the derivation moves into Spec, TP to be case licensed. Chomsky (1995) proposes that this movement takes place covertly, where the associate adjoins to there. This movement is motivated by the need to check its case feature, since its original position does not allow it to do so (see Lasnik 1995, however, for discussion).

[5] Munn (1999) notes briefly that plural agreement with CNPs in British English is possible only in a Spec-head relationship, but not via agreement under government (where the CNP lies beneath the target of agreement); however, he does not provide a further explanation for why this should be the case. The claim I make in this paper is similar, but not identical to this. I do not commit to a Spec-head relationship being necessary for plural agreement, since this appears to be too strong given that plural agreement is possible on anaphors also (which, as detailed below, I treat as the same process). Furthermore, the relevant structural configuration is shown here to hold at LF.

[6] The associate DP is the post-copula DP that is understood as the 'subject' of the construction (using 'subject' in a somewhat informal manner). 
For different reasons, both Lasnik (1995) and Bobaljik (2002) propose that the associate of an existential construction moves into the higher position at some point in the derivation.

Contrasted against this style of approach are approaches where the associate stays low throughout the derivation. Approaches of this type are Bošković (1997) and Witkós (2004), where it is assumed that there and the associate are somehow related, and there either moves down covertly (Bošković) to adjoin to the associate, or they are initially both merged low and there moves away (Witkós). Furthermore, Bjorkman \& Zeijlstra (2015) propose that the associate always remains low in the derivation, with there merged directly into Spec, TP to fulfill the EPP requirement of English. Support for this style of approach comes from den Dikken (1995), who points out that the evidence suggests that (at least at the level of LF) the associate does not appear to be in Spec, TP.

(13) (a) Some applicants $i$ seem to each other $i$ to be eligible for the job.

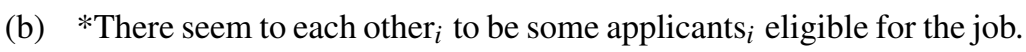

(c) Someone S seems to his $_{i}$ mother to be eligible for the job.

(d) *There seems to his ${ }_{i}$ mother to be someone $i$ eligible for the job.

Were the associate DPs to move to the higher position at LF in the ungrammatical examples, then we would expect that the anaphoric elements in (13b) and (13d) would be correctly bound, contrary to fact. Given that the sentences in (13b) and (13d) are ungrammatical, we can conclude that the associate does not raise to Spec, TP to replace there covertly (see also Sobin 2004 for further discussion). In accordance with $L F$-Visibility, plural agreement is not able to be controlled by a CNP in an existential construction.

\subsection{Scope reconstruction}

When we consider reconstruction for scope, we see that simply raising above the target at some point in the derivation is not sufficient. Rather, the CNP needs to remain in the high position at $\mathrm{LF}$ for plural agreement to be possible.

(a) A northern team is likely to be in the final. $\quad \exists \gg$ likely / likely $\gg \exists$

(b) A northern team are likely to be in the final. $\exists \gg$ likely $/ *$ likely $\gg \exists$

For raising sentences, I follow Fox (1999), who proposes that a reconstructed reading arises when there is a mismatch between the place where a DP is positioned in the surface form of a sentence, and the position where it is interpreted. Throughout the derivation, the DP moves from the non-finite Spec, TP to the higher, finite Spec, TP, creating two copies of the DP. If both pronunciation and interpretation choose to use the higher copy, then the DP will take wide scope in the sentence. Scope reconstruction arises when different copies are chosen for interpretation and pronunciation: the copy that is interpreted is in a structurally lower position than the copy that is pronounced. 
(15)

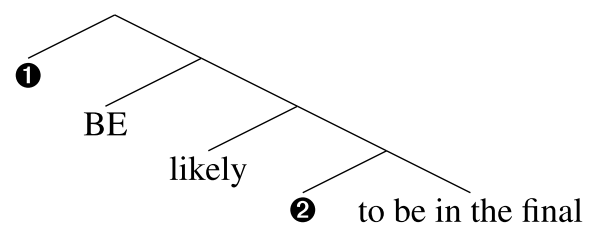

In both sentences in (14), the CNP is pronounced in position $\mathbf{P}$ in the tree. When interpreted with wide scope with respect to likely, $\mathbf{0}$ is also its position of interpretation. When it reconstructs, however, it is interpreted in position 2. Thus, in the reconstructed reading, the CNP lies in position 2 at LF, whereas in the non-reconstructed reading, the CNP lies in position $\mathbf{0}$. In accordance with LF-Visibility, plural agreement is licensed when the CNP does not reconstruct (position (1), but not licensed when it does (position 2).

\subsection{Predicate/subject readings}

The final difference between singular and plural agreement comes from predicate constructions, as identified by den Dikken (2001). Recall that the predicate reading is not available with plural agreement. The relevant examples and readings are repeated below.

(16) (a) The best committee is theirs. committee $=\boldsymbol{V}$ subject $/ \boldsymbol{V}$ predicate.

(b) The best committee are theirs. committee $=\boldsymbol{V}$ subject $/ \boldsymbol{X}$ predicate

(17) (a) The best committee belongs to them.

(subject reading)

(b) The committee that they belong to is the best committee. (predicate reading)

In order to understand why plural agreement disallows the predicate reading, we must understand the difference in structure between the subject and the predicate reading. For the subject reading, I assume that the structure is as follows, where the best committee moves from the specifier of the predicative XP into the sentential subject position (Spec, TP) (see den Dikken 2007).

(18) Subject reading

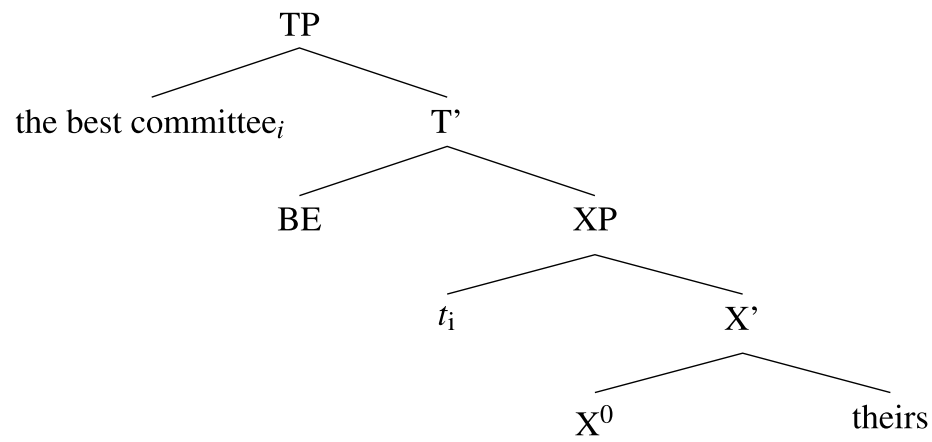


By way of contrast, in the predicate reading structure, the noun phrase containing the CNP raises from the predicate position in the predicate XP to Spec, TP, as follows below. This is a predicate inversion structure (den Dikken 1998).

\section{Predicate reading}

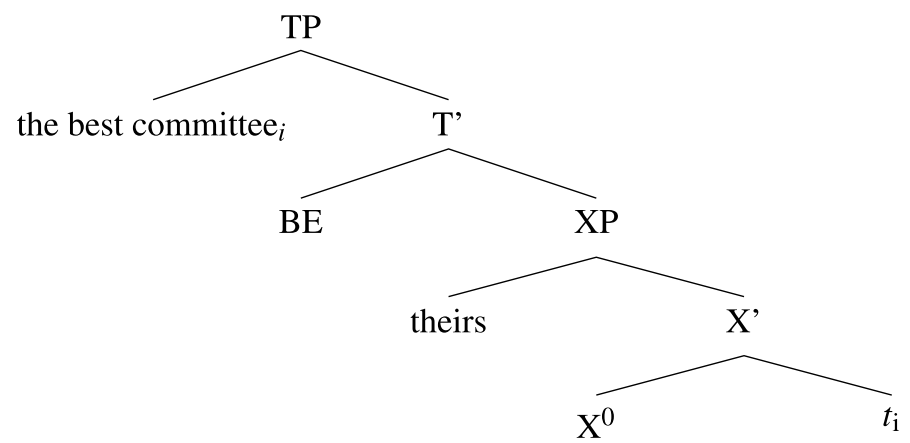

The crucial difference between the subject and the predicate reading of the sentences is where the CNP starts out. In the predicate reading (19), the best committee is the predicate nominal, whereas in the subject reading (18), it is the subject of the predicate construction. This distinction is important in light of the findings by Heycock (1995), who argues that predicates must always reconstruct into their base position at LF, based in part on the following (Heycock 1995: 546). Given the ungrammaticality of (20), Heycock argues that the moved predicate reconstructs, inducing a Condition $\mathrm{C}$ binding violation.

(20) $*$ [How proud of $\left.\mathrm{John}_{i}\right]_{k}$ do you think he ${ }_{i}$ is $\mathrm{t}_{k}$ ?

Taking it to be true that predicates reconstruct at LF, then we can see that LF-representations for the subject and predicate readings are as in (21) and (22) respectively.

(21) Subject reading at $L F$

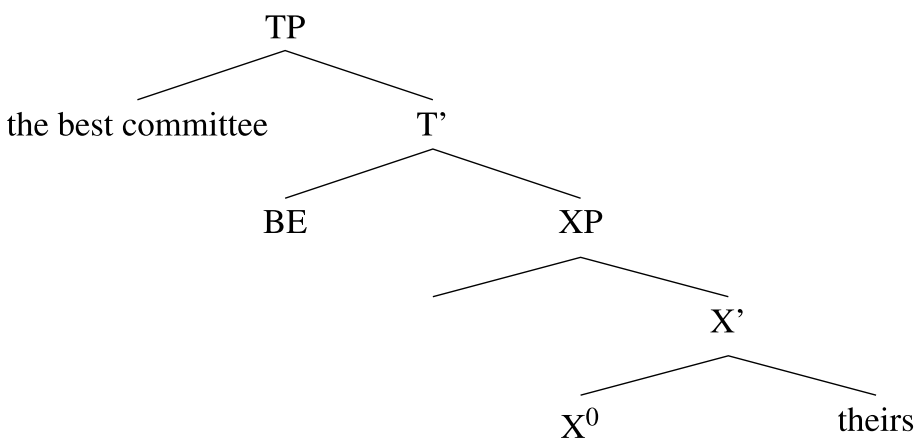




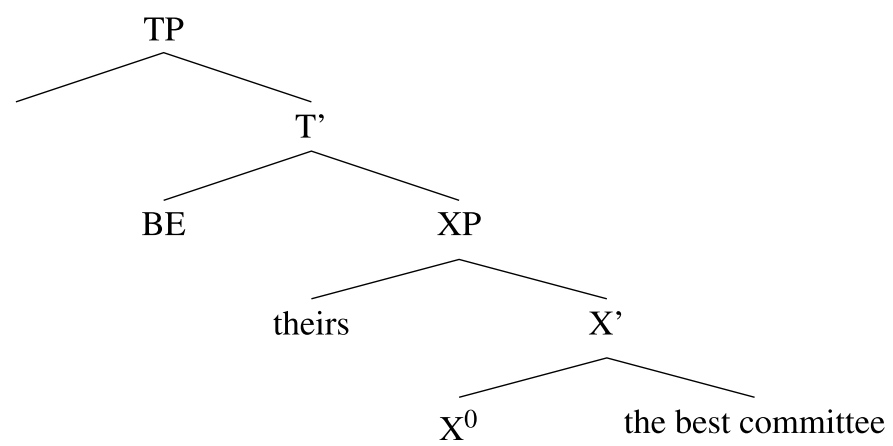

In both of these sentences, the best committee is the controller of agreement. Furthermore, den Dikken (2007) shows that with predicate constructions in English, it is always the element that lies in Spec, TP on the surface that is the controller of agreement, irrespective of whether it is a regular structure (21) or an inversion structure (22) where the predicate raises to Spec, TP. In accordance with LF-Visibility, plural agreement is not possible in the predicate reading because the controller of agreement, the best committee, which is the reconstructed predicate, lies underneath the target, $T^{0}$, at LF, and so it does not c-command the target of agreement. Again, we see that $L F$-Visibility describes where plural agreement is allowed and disallowed.

\subsection{Summary}

In this section, we have seen that we can predict where plural agreement is allowed or disallowed based on the structural position of the CNP that controls agreement. In all instances, plural agreement is disallowed when the CNP lies in a position beneath the target at LF. That LF is the crucial requirement is shown by the scope reconstruction cases and predicate readings, where simply moving to Spec, TP at some point in the derivation is not enough to license plural verbal agreement. Rather, it has been shown that the CNP needs to remain in the high position, and not reconstruct lower.

Before moving on to other instances of restrictions on plural agreement, I wish to consider whether we really want to invoke a structural restriction on plural agreement here. An anonymous reviewer suggests that the reason why plural agreement is not seen in existential constructions could simply be the result of the combination of two effects of frequency: (i) CNPs prefer in general to take singular agreement (as shown in a corpus study in Levin 2001, which will be discussed in Section 5 below) and (ii) existential constructions allow for singular agreement even when there is a plural associate (Meechan \& Foley 1994, Sobin 1997). Coupled together, these would give a preference for singular agreement in existential constructions. 
In order to further verify the data, I ran a small corpus study into how agreement is resolved with CNPs. Using the British National Corpus, I tested what agreement was found in present tense existential constructions where the associate was a CNP. ${ }^{7}$ The results of this search are given in Table 1 . They show that, aside from a few cases with three CNPs, plural agreement is systematically absent in existential constructions when the associate is a CNP. Importantly, this does not appear to be a preference by speakers, but the near-complete absence of plural agreement (save for with three nouns), even when the CNP associate is one where plural agreement is often shown (see especially team). This suggests that this is a genuine restriction of agreement, rather than a dispreference. ${ }^{8}$

\begin{tabular}{lcc}
\hline Noun & Instances of singular agreement & Instances of plural agreement \\
\hline Team & 11 & 0 \\
Committee & 14 & 0 \\
Group & 91 & 5 \\
Government & 14 & 0 \\
Couple & 1 & 0 \\
Staff & 9 & 2 \\
Crowd & 3 & 0 \\
Band & 10 & 0 \\
Department & 8 & 0 \\
Clergy & 0 & 0 \\
Company & 8 & 0 \\
Minority & 11 & 4 \\
Majority & 23 & 0 \\
Press & 2 & 0 \\
Council & 19 & 0 \\
Family & 6 & 0 \\
\hline$n$ & 230 & 11 \\
\hline
\end{tabular}

Table 1

Singular versus plural agreement when the CNP is the associate of an existential construction.

It should be noted as well that the lack of plural agreement in scope reconstruction cases and predicate/subject readings cannot be due to the combination of singular agreement preferences either, as discussed above. Unlike in existential constructions, raising constructions do not allow a plural controller to control both

[7] The corpus search was conducted between 25 October 2015 and 27 October 2015, using the British National Corpus hosted by Brigham Young University.

[8] As to why plural agreement is found on a few examples with group, staff and minority, I do not have an answer, noting only that they show a deviant pattern with respect to the other CNPs in the survey. 
singular and plural agreement on the verb (23); neither do predicate inversion structures (24). Thus, the restrictions on plural agreement cannot come from the interplay of preferences.

(23) *Some dogs is likely to be barking again.

(24) *The two best players in the league is Jones and McCullum.

Under LF-Visibility, however, we have a unifying account for the restrictions on plural agreement, albeit a descriptive generalisation for the time being. ${ }^{9}$ In the next section, I offer an account of why LF-Visibility should hold.

\section{LF-VISIBILITY EXPLAINED}

In the previous section, I have shown that the generalisation regarding plural agreement with CNPs in English is that plural agreement is only licensed when the controller c-commands the target at the level of LF. Agreement, within minimalist assumptions, has been taken to happen either during the syntactic derivation (Chomsky 2000 et seq and much other work in the minimalist framework) or postsyntactically (Bobaljik 2008). It is then curious why the position where CNPs are semantically interpreted should make such a difference to its licensing potential of different agreements. That is, why is it that the level of LF apparently seems so crucial for where plural agreement is licensed with CNPs? The goal of this section is provide a theoretical explanation for this empirical generalisation (i.e. LF-Visibility). The answer that I suggest is composed of two parts. First, we need to understand why plural agreement should differ from singular agreement, and, second, what it is that enforces this difference. The answer I will propose to the first issue is that plural agreement is triggered by the semantic number specification, which I will show to be plural; in contrast, singular agreement reflects the morphological features of the CNP (Corbett 1979). The second part of the answer I will propose is the result of the nature of AGREE (Chomsky 2000), and, specifically, how AGREE treats semantic features differently from morphological features. It should be noted at the outset that the implementation that I propose is just one possible way of deriving LF-Visibility and that this empirical generalisation holds independently of the assumptions outlined below.

[9] An anonymous reviewer, also a speaker of British English, notes that their judgements do not match those reported in this section. This raises the question of whether there is further variation than LF-Visibility. This is an issue worthy of attention in future work. However, I have not encountered other speakers who share the judgements of the reviewer, and at this stage am unable to provide further discussion on this point. 


\subsection{Morphological versus semantic features}

From the discussion above, it seems that it must be the case that CNPs in English are simultaneously singular and plural. ${ }^{10}$ This follows from the existence of sentences where both agreements are triggered in the same clause, see (4) and (10) above. Furthermore, we can see that when the CNP controls singular agreement on the verb, it can combine felicitously with a predicate that obligatorily takes a plural subject, such as gather.

(25) (a) The committee is gathering now to discuss the proposal.

(b) The government gathered to debate the ongoing security situation.

Collective predicates like gather require a semantically plural subject, as can be shown by the following. ${ }^{11}$

(26) (a) The faculty members gathered to discuss the proposal.

(b) *The faculty member gathered to discuss the proposal.

It is clear then that the CNPs must be in some way specified as plural (or nonatomic, see footnote 11). However, they must also be able to be singular, since they clearly are able to control a range of singular agreements. I propose that we resolve this issue not by positing two distinct features, as Elbourne (1999) does (see Section 4 for discussion), but rather see them as two halves of the same feature (see also Wechsler \& Zlatic 2000, 2003). That is, the number $\phi$-feature for CNPs is valued both singular and plural.

How is this manifested? First, it should be pointed out that such a mismatch in the specification of $\phi$-features is not just seen with collective nouns in English, but such cases are observed with other nouns and in other languages, for instance grammatical gender. Corbett (1983) shows that Russian has a similar split along morphological/semantic lines, such as with the following.

$$
\begin{aligned}
& \text { Novyj vrač skazala. } \\
& \text { new.MASC doctor said.FEM } \\
& \text { 'The new doctor said.' }
\end{aligned}
$$

[10] I make this claim here for English, but perhaps it is the case in other languages too. Corbett (2000: 188-191) cites Spanish, Old Church Slavonic, Paumarí, Kabardian and Samoan as examples of languages that also show plural agreement able to be triggered by collective nouns. I leave a full cross-linguistic investigation to future research.

[11] An anonymous reviewer points out that mass nouns in fact license gather while being morphologically singular, e.g. the fog is gathering. However, one might not want to call mass nouns 'plural' in reference. The licensing of gather is then likely restricted to non-atomic predicates, which encompass both mass nouns and plurals (Chierchia 1998). However, all that is crucially relevant for our purposes is motivating the assumption that CNPs are not semantically singular when they are morphologically marked as such, so I abstract away from this issue somewhat. I refer the reader to Champollion (2015) and references therein for an overview of the licensing requirements of collective predicates. 
In (27), we see that the agreement on the attributive adjective is masculine, but the agreement on the verb is feminine. Corbett notes that this sentence could be felicitously uttered when the doctor is female. This state of affairs arises because vrač 'doctor' is morphologically masculine, but can also refer to female doctors. Thus, we have the same situation as with collective nouns: with vrač, the semantic value can differ from the morphological specification, but this time the mismatch stems from the gender $\phi$-feature.

Another Slavic language, Bosnian/Croatian/Serbian, shows the same phenomenon, this time with number and gender, and this has been the subject of a large-scale investigation by Wechsler \& Zlatić (2000, 2003). ${ }^{12}$ Sentences such as (28) show that some nouns in this language have the ability to trigger mismatched agreements. The adjective and demonstrative agree in the feminine singular form, while the agreement on the participle and auxiliary is (neuter) plural.

Ta dobr-a deca su $\quad$ doš-l-a
that.F.SG good-F.SG children AUX.3PL come-PPRT-NT.PL
'Those good children came.'

Wechsler \& Zlatić (2003) propose that agreement features come in two types, CONCORD and INDEX. ${ }^{13}$ Couched in HPSG (Pollard \& Sag 1994), CONCORD features correspond most closely to the inherent grammatical (declension) information on the noun, whereas INDEX features correspond more closely to the semantic information of the noun.

$$
\text { DECLENSION - CONCORD - INDEX — SEMANTICS. }
$$

While there is usually a complete matching of all features on the scale in (29), there are cases where the semantic information mismatches with the declension information of the noun. In these cases, there is a mismatch somewhere along the chain, for instance in (30). If one category targets the CONCORD information, and another the INDEX information, then this will result in a mismatch, such as in (28) above.

DECLENSION - CONCORD $\|$ INDEX - SEMANTICS.

[12] Completing the gamut of $\phi$-feature mismatches, we arguably see person mismatches in person features with so-called Imposter constructions (Collins \& Postal 2012). These will be briefly discussed at the end of this section.

[13] Technically, in their proposal there are potentially three relevant features, since semantic information can become relevant to agreement. If semantic features enter into agreement and there is a mismatch between CONCORD, INDEX and SEMANTICS, then there is a threeway mismatch. They give the noun braca 'brothers', and claim that there is the following specification: DECLENSION $\Leftrightarrow$ CONCORD \| INDEX $\|$ SEMANTICS. The distinction between all three features is not relevant to the matters at hand here so I only discuss CONCORD and INDEX. There has been criticism of the need for three types of agreement features in their system by Alsina \& Arsenijević (2012), who argue that a morphological/semantic split is all that is needed for the Bosnian/Croatian/Serbian data (however, see Wechsler \& Zlatić 2012 for a reply to this proposal, as well as Hristov 2013). 
I assume a similar idea to Wechsler \& Zlatić, but instead of these two agreement categories representing different, if interrelated, features, I assume that they simply instantiate the same feature; in short (at least some) $\phi$-features come with a morphological half and a semantic half. This is not the case for all features of course - Case, for instance, is likely not semantically interpretable (however, see Butt 2006 and Svenonius 2007 for discussion) - but some features, such as $\phi$-features on nouns, are expressed morphologically and interpreted by the semantics. In the usual case, the values for each will match, as in (31), but in other cases there will be divergent values for each half of the feature, (32). Below, and throughout the rest of this paper, I use the abbreviations $u \mathrm{~F}$ for the value that the morphology receives and $i \mathrm{~F}$ for the value that the semantics receives.
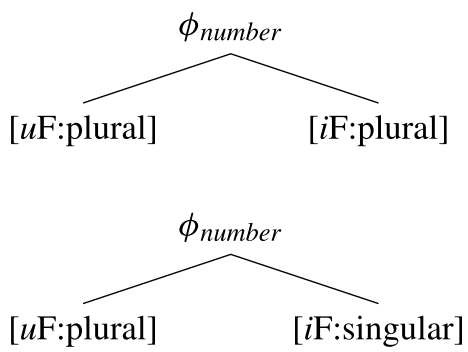

Here, I propose that we should analyse CNPs in this manner as well; their interesting behaviour with regard to singular versus plural agreement arises because their number $\phi$-feature contains a divergence between the values on the $u \mathrm{~F}$ and the values on the $i \mathrm{~F}$. CNPs are morphologically singular because their $u \mathrm{~F}$ is singular, while their $i \mathrm{~F}$ is valued as plural, accounting for their plural properties.

Number specification for CNPs

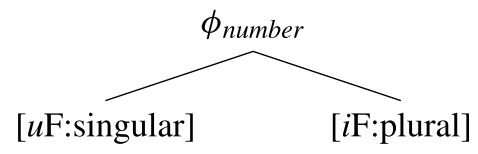

An anonymous reviewer raises the question of how this proposal can account for the fact that with predicates that apply to the CNP as a whole, and not the individual members, singular agreement is required (examples below taken from Huddleston \& Pullum 2002: 502).

(34) (a) The committee consists/*consist of two academic staff and three students.

(b) One committee, appointed last year, has/?have not yet met.

The answer could be as simple as that CNPs have a variable $i \mathrm{~F}$ :\#, which is either singular or plural. For plural agreement to be possible (though not necessary), the variant that is $[u \mathrm{~F}$ :singular, $i \mathrm{~F}$ :plural $]$ is used. However, CNPs 
could also be specified as $[u \mathrm{~F}$ :singular, $i \mathrm{~F}$ :singular $]$, which could only control singular agreement. Predicates that necessarily say something about the CNP as a whole could be restricted to combining with this non-hybrid CNP variant. Such a step is perhaps necessary at any rate, given that there is clearly the ability to have singular reference to a CNP, a fact that would need an additional semantic mechanism of converting pluralities to singularities if the number information on CNPs were always [ $u \mathrm{~F}$ :singular, $i \mathrm{~F}$ :plural]; see Smith (2015) for discussion. However, the key point to take away is that CNPs that have the ability to control plural agreement have this ability due to the fact that their semantic number specification (the value carried on the $i \mathrm{~F}$ for number) is plural.

This approach easily extends to other cases of morphology/semantics mismatches (see Smith 2015). Consider once more grammatical gender, which in many cases is simply a case of morphosyntactic categorisation without having a semantic basis (though see Dowty \& Jacobson 1988 for an alternative approach where it is semantically based). Grammatical gender can then simply be the morphological half of a gender feature inherent on the noun. Since there are no semantic consequences to this value, we can assume that the semantic value is absent. For instance, in German, der Tisch 'the.MASC table' is grammatically masculine, as evidenced by the shape of the determiner, and we can assume that in the lexical entry for Tisch there is a morphological gender feature that is valued masculine but the semantic gender value is absent.

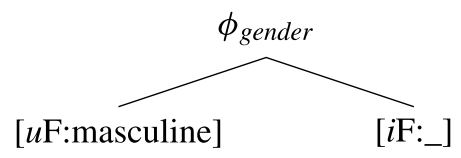

Now, some nouns will also have an interpretable gender feature. For instance, nouns of human reference are likely to have some form of semantic gender. In the above example from Russian (27), vrač 'doctor' is morphologically masculine (as shown by the agreement on the adjective), but it is semantically feminine, since the feminine agreement on the verb indicates that the doctor is female. We can then posit that in the example above, vrač has the following gender classification, with the split between morphological and semantic reference noted in the divergent values on the feature.

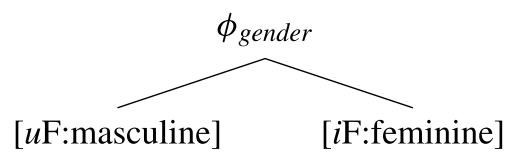

In another case, pluralia tantum nouns can be analysed as having [ $u \mathrm{~F}$ :plural] inherent to the noun, but [ $i \mathrm{~F}:$ singular] when used in singular reference (I want these scissors, when pointing to a single pair). Similarly, Imposter constructions (Collins \& Postal 2012) can be seen as having a mismatch on their person 
feature. In the following, the DP this columnist refers to the first person, but the morphological shape of it is third person. ${ }^{14}$

(37) This columnist, for one, does not believe the official statement.

In sum, we have seen a number of cases of morphology-semantics mismatches on $\phi$-features, which can be modelled if we assume that $\phi$-features themselves decompose into a morphological $u \mathrm{~F}$ and a semantic $i \mathrm{~F}$.

\subsection{Semantic Agreement, and AGREE}

With this view on features in mind, we can begin to understand why LF-Visibility holds. In brief, the explanation that I pursue is that the operation of AGREE is distributed over two domains of the grammar, in the narrow syntax and in the post-syntactic PF branch, and that there is a directional difference between the two. ${ }^{15}$ The crucial consequence of this is that $i$ Fs can be involved in agreement only in the narrow syntax, but not the PF branch, for reasons that will soon become clear. $u$ Fs, on the other hand, can be targeted either in the narrow syntax or in the PF branch. This asymmetry will allow us to understand why semantic agreement appears to be more restricted.

Above, I have proposed that $\phi$-features are composed of two halves, one half that is legible to the morphological component and one half that is legible to the semantic component. I assume Distributed Morphology (Halle \& Marantz 1993), and that syntax operates on feature bundles that are later subject to Vocabulary Insertion, where phonological exponents replace these feature bundles. Morphology applies post-syntactically, operating on and manipulating syntactic structures. This means that in the syntactic derivation, both $i \mathrm{Fs}$ and $u \mathrm{Fs}$ are paired together. However, at the point of transfer I assume that they are sent to their respective interfaces. Morphological $u$ Fs are the only features present in the PF branch, and semantic $i$ Fs are the only features in the LF branch. This does not mean that $i$ Fs can have no morphological reflex of course: if they donate an agreement value to $\mathrm{a}(u \mathrm{~F})$ target in the narrow syntax, then this value will be morphologically realised on the target. Below, I demonstrate where the types of features are located in the syntactic (and post-syntactic) derivation, assuming a single-output model of the syntax (Bobaljik 1995, 2002).

[14] An anonymous reviewer suggests that so-called 'pancake sentences' (Enger 2004, 2013) might have the same basis. There are further examples of morphology/semantics mismatches, for which I refer the reader to Pollard \& Sag (1994) and Smith (2015) for discussion.

[15] I use the term 'narrow syntax' to clearly distinguish it from syntactic operations that happen after the point of Transfer. 


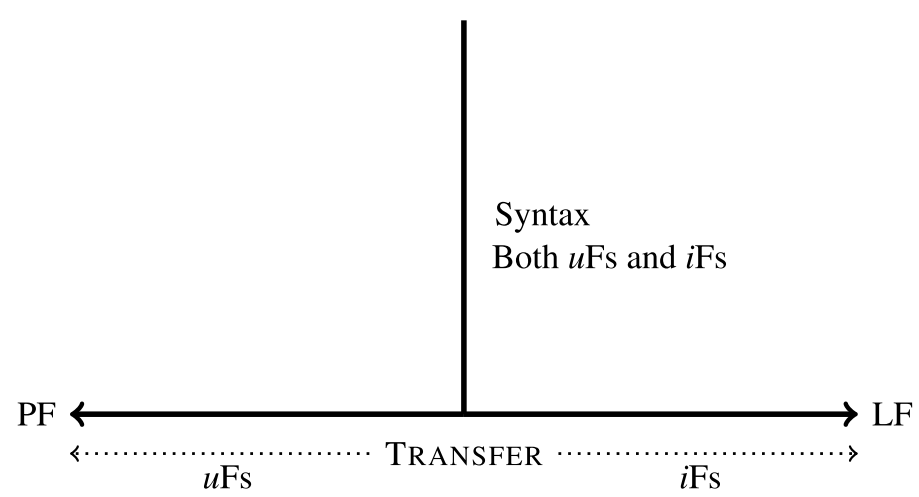

I further assume a modified version of the AGREE model given in Arregi \& Nevins (2012) (see also Benmamoun, Bhatia \& Polinsky 2009, Bhatt \& Walkow 2013), where AGREE is treated not as a process that matches targets and controllers and immediately copies the value. Rather, AGREE is formed of AGREE-LINK, which matches targets and controllers, and AGREE-COPY, which copies the values from the controller to the target. Crucial for us is that AGREE-COPY does not immediately happen once AGREE-LINK has matched two elements together. The version of AGREE that Arregi \& Nevins give is below. One can see that AGREE-LINK is treated by Arregi \& Nevins as a syntactic process, and AGREE-COPY as a post-syntactic process. ${ }^{16}$

(39) AGREE in Arregi \& Nevins (2012) (to be revised below)

Agreement by Probe with Goal proceeds in two steps.

(a) AGREE-LINK: in the syntax, a probe has unvalued $\phi$-features that trigger Agree with a goal (possibly more than one). The result is a link between probe and goal.

(b) AGREE-COPY: in the Exponence Conversion module (= a subpart of the post-syntactic PF branch, PWS), the values of the $\phi$-features of the goal are copied onto the probe linked to it by AGREE-LINK.

This, however, does not suffice for our purposes, since I assume that $i$ Fs are not present in the post-syntactic PF component, and so under this view they would be unable to play a role in AGREE-COPY. Thus, in order to account for the existence of semantically motivated agreement, we must assume that AGREE-COPY is able to (but does not have to) happen at an earlier stage of the derivation, when both $i$ Fs and $u$ Fs are present. The facts from CNPs in English suggest that this

[16] Note that in Arregi \& Nevins's formulation and in the discussion below, 'probe' is what I have been calling 'target' and 'goal' is 'controller.' 
earlier process should operate on LF structures; thus, I propose that AGREE-COPY can happen at the point of transfer, after copies have been chosen, but before features are sent to the interfaces, allowing $i$ Fs to play a role in agreement. ${ }^{17}$ The minimally reformulated version of AGREE that I propose is then as follows.

(40) Agreement by Probe with Goal proceeds in two steps.

(a) AGREE-LINK: a probe has unvalued $\phi$-features that trigger Agree with a goal (possibly more than one). The result is a link between probe and goal.

(b) AGREE-COPY: after the syntactic derivation, the values of the $\phi$ features of the goal are copied onto probe linked to it by AGREELINK.

(i) If AGREE-COPY happens at the point of transfer, this requires that goal c-command the probe.

Annotated onto the Single-Output model of the grammar (Bobaljik 1995, 2002), AGREE then operates as follows. ${ }^{18}$

The decomposition of AGREE

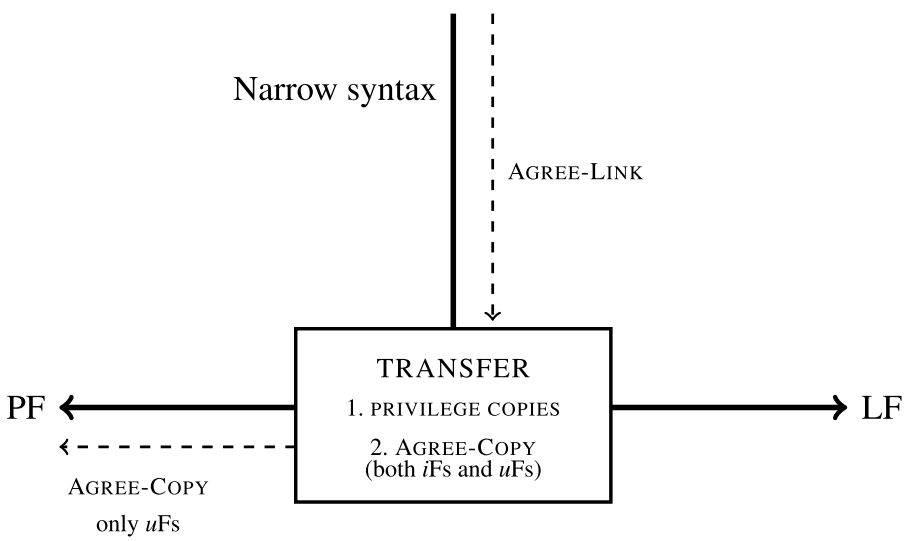

It is worthwhile to elaborate a little further on the consequences of viewing AGREE in this manner. First, not only does it capture the facts of CNPs in English (I spell out the derivations in detail below in Section 3.3), but it also captures

[17] See also Glushan (2013) and Smith (2015) for discussion of Russian Quantified NPs (Pesetsky 1982, Franks 1994, 1995, Bošković 2006) that adds further support to this conclusion. The conclusion in brief in Smith (2015) is that plural agreement with QNPs is only allowed when the QNP occupies Spec, TP at the level of LF; otherwise, only default neuter singular agreement is possible. The facts are too complicated to go into here for reasons of space; however, I refer the reader especially to Glushan (2013) for extensive discussion and motivation for semantically motivated agreement being restricted in this manner in Russian.

[18] PRIVILEGE in the diagram refers to the process of selecting where $i$ Fs and $u$ Fs are to be realised. 
the insight of Baker (2008) that AGREE should be viewed as an operation that looks upwards and downwards in the structure. The formulation of AGREE in minimalist approaches is subject to keen debate, and his point is not in itself uncontroversial: AGREE in its original formulation (Chomsky 2000, 2001) was a process that looked only downwards in the structure (the probe needed to ccommand the goal), a view that has recently been defended by Preminger (2011, 2013, 2015) and Preminger \& Polinsky (2015).

Yet, the proposal that AGREE only looks downwards has been criticised, notably by Wurmbrand (2011, 2012a, b), Zeijlstra (2012) and Bjorkman \& Zeijlstra (2015), who argue that there are clear instances of agreement phenomena that look upwards. For instance, Zeijlstra (2012) argues that agreement looks uniformly upwards, based in part on data from Negative Concord (Zeijlstra also considers Sequence of Tense, and instances of Multiple Agree). In brief, Zeijlstra argues that elements showing negative concord all lie structurally beneath the Negative Operator. Therefore, in order to receive a value from the operator, they must be able to look upwards in the structure. Furthermore, Wurmbrand (2011, $2012 \mathrm{a}, \mathrm{b}$ ) has argued for an 'upwards-only' model of agreement, based on facts from participial agreement, raising constructions, binding and control.

Despite these attempts to provide a uni-directional formulation of AGREE, either downwards or upwards, Baker shows that there is evidence from within Indo-European languages that agreement must go both up and down. For instance, Icelandic seems to show that agreement can look downwards, since T can undergo agreement with a nominative object (example from Bobaljik 2008). ${ }^{19}$

(42) Jóni líkuðu Pessir sokkar

Jon.DAT like.PL these socks.NOM

'John likes these socks.'

[Icelandic]

However, Baker also shows that in Icelandic, predicate adjectives also undergo agreement with their subject, which seems to indicate that agreement can also look upwards (assuming that the predicate adjective does not c-command the predicate subject at any point (den Dikken 2007)).

$$
\begin{array}{lll}
\text { María } & \text { er } & \text { gód } \\
\text { Maria.NOM is } & \text { good.F.SG.NOM }
\end{array}
$$

'Maria is good.'

Baker proposes that this shows that there is some flexibility within AGREE, such that as long as c-command is respected between controller and target, then along with the usual assumptions regarding locality, etc., AGREE can happen in

[19] The direction of agreement is subject to parametric variation for Baker. Indo-European languages can show either upwards agreement or downwards agreement, while Bantu languages can only show upwards agreement. Baker further gives Burushaski as a language that shows only downwards agreement. In light of this, it would of course be interesting to look at whether Burushaski shows evidence for $i \mathrm{~F}$ agreement; however, I leave this for future research. 
either direction. I will follow Baker in this regard, with one important qualification: the flexibility in agreement direction holds for AGREE-COPY only in the PF branch - if AGREE-COPY happens at the point of transfer, crucially before the PF component, then it is only allowed to look upwards.

With AGREE-COPY seemingly able to look upwards and downwards in the structure in PF, it might be questioned why AGREE should operate in this manner, with a directional restriction at transfer and none in the post-syntax. Such an approach has the welcome result here that we can explain the restrictions on semantic agreement with CNPs. The theory of AGREE has been dominated by morphological agreement, but one of the proposals of Wurmbrand (2012a) is that this looks at the issue in the wrong way. If AGREE is to be seen as a general operation that copies features from controller to target, then morphological agreement is only one phenomenon that falls under AGREE. Binding can also be seen as involving AGREE (Reuland 2001, 2011, Hicks 2009, Wurmbrand 2012a). What Wurmbrand (2012a) points out is that any agreement operation that involves a semantic value (here, an $i \mathrm{~F}$ ) looks upwards in the structure. Thus, binding, control, negative concord and sequence of tense all look upwards in the structure. Morphological agreement, which involves a dependence between two $u$ Fs, can apparently go either way. This insight is maintained in the formulation of AGREE given here. However, as to why AGREE-COPY is restricted in this manner, I do not offer an answer here, other than to mention that this is where the data lead us to. ${ }^{20}$

This version of AGREE captures the difference between agreement that targets an $i \mathrm{~F}$ and one that targets a $u \mathrm{~F}$. Since the latest (and earliest) point that $i \mathrm{Fs}$ can be targeted for AGREE-COPY is at the point of transfer, agreement involving an $i \mathrm{~F}$ is only possible if the $i \mathrm{~F} \mathrm{c-commands} \mathrm{the} \mathrm{target.} \mathrm{However,} \mathrm{morphological} \mathrm{agreement}$ can take place in the PF component, where direction is not at issue, and thus the target can look either upwards or downwards.

[20] Thoms (2013) claims that the reason why CNPs remain in the high position with plural agreement is due to the fact that the movements of the CNP are solely motivated by the EPP, and reconstruction is prohibited by the PEPPER principle of Nevins \& Anand (2003), where movement that is solely EPP related never reconstructs. Thoms offers an alternative proposal to the one presented here, including data to do with scope interactions of the CNP with negation which prima facie appear to contradict LF-Visibility, such as the following where Thoms claims that with the contracted $n$ ' $t$ form of negation, negation must scope above the CNP (i). However, this seems to be too strong given (ii).

(i) An English team haven't won away in Europe this season.

$* \exists \gg n ' t / n ' t \gg \exists$

(ii) Some English team haven't turned up to the tournament they were booked to play in, but I forget their name.

$\exists \gg n ' t / n ' t \gg \exists$

If Thoms' data are correct, then there seems to be a problem. However, this does not necessarily mean that they reconstruct to a position beneath T. Negation could be interpreted here in a high operator (Zeijlstra 2004). I leave this matter open, acknowledging that it may end up causing a problem for the account here, and hope that future research will shed further light on the data. 


\subsection{Deriving the restrictions on CNP plural agreement}

Before moving on to the discussion of how this approach fares against previous analyses of the phenomena, I wish to spell out the derivations of the phenomena under discussion, and show how the system outlined derives the restrictions on plural agreement with CNPs.

\subsubsection{Scope reconstruction}

As noted above in Section 2.2, I follow Fox (1999) and treat scope reconstruction cases here as an instance where two copies of a DP are merged into the tree, and there is a mismatch between the copy chosen for interpretation and the copy chosen for pronunciation. The copy chosen for pronunciation is the higher copy, and the one chosen for interpretation is the lower copy. In the approach here, we can say that the split is not between two copies that are marked for interpretation and pronunciation, but rather the mismatch occurs when the $u$ Fs are realised (pronounced) in a position different from where the $i F s$ are realised (interpreted).

Consider first a raising construction where the CNP is both pronounced and interpreted in the matrix clause, above likely. Recall that, in this case, both plural agreement and singular agreement are possible. I assume that a northern team is initially merged in the lower clause, before raising into the higher clause, in order to satisfy the EPP requirement of English.

(44) A northern team is/are likely to be in the final. $\quad \exists \gg$ likely / likely $\gg \exists$

In the structure below that corresponds to (44), we see that the $i$ Fs of the CNP are realised in the same position as the $u \mathrm{Fs}^{21}$ Now, during the narrow syntax, AGREE-LINK links the higher T to the CNP. If AGREE-COPY chooses to take its value from the $i \mathrm{Fs}$, the result is semantic agreement. This is possible here, because AGREE-COPY happens at the point of transfer and is able to take a value from the $i$ Fs on the CNP, as they c-command T. The structure below is the structure that is sent to the interfaces.

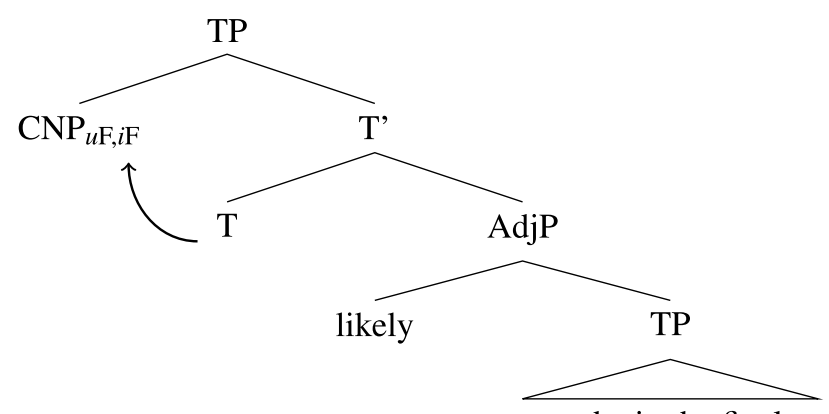

to be in the final

[21] Irrelevant details in the structure are ignored. 
The more interesting case happens when there is reconstruction for scope. Here, there is a discrepancy between the position of the $u$ Fs of the CNP, which are realised in the high position, and the $i$ Fs of the CNP, which are realised in the low position. Since the $i \mathrm{Fs}$ are beneath $\mathrm{T}$, they are unable to be targeted by AGREE-COPY at the point of transfer, since there the target must look upwards in the structure. However, they are also unable to be targeted by AGREE-COPY in PF, since the $i$ Fs are not in that component, having already been transferred to the semantic component. Thus, the only possibility is that AGREE-COPY takes its value from the $u$ Fs of the CNP, which can happen either at transfer or postsyntactically, with the result that the verbal agreement is singular.

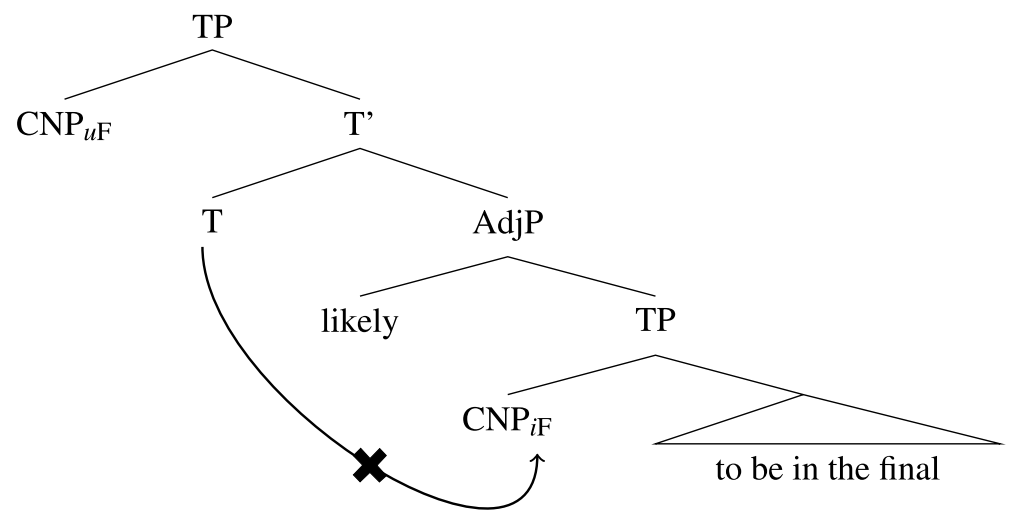

\subsubsection{Predicate/subject readings}

In addition to capturing the facts of why semantic agreement is not possible when the CNP reconstructs, we also gain an explanation for the predicate/subject alternations given by den Dikken (2001). The same principle is at play here. In Section 2.3, I motivated the proposal that in the subject reading of the sentences, the CNP lies in Spec, TP at LF, whereas in the predicate readings, it lies beneath $\mathrm{T}$, since as a predicate, it must reconstruct into its base position at LF ( $c f$. Heycock 1995 and the data in (20)). In both readings, the CNP is pronounced in Spec, TP, since the $u$ Fs of the CNP remain there; however, in only the predicate reading, the $i$ Fs reconstruct. Thus, semantic agreement is possible in the subject reading but not the predicate reading. The two structures are given below. ${ }^{22}$

[22] Irrelevant structural details are again ignored. 
(47) Subject Reading: the best committee $=$ subject

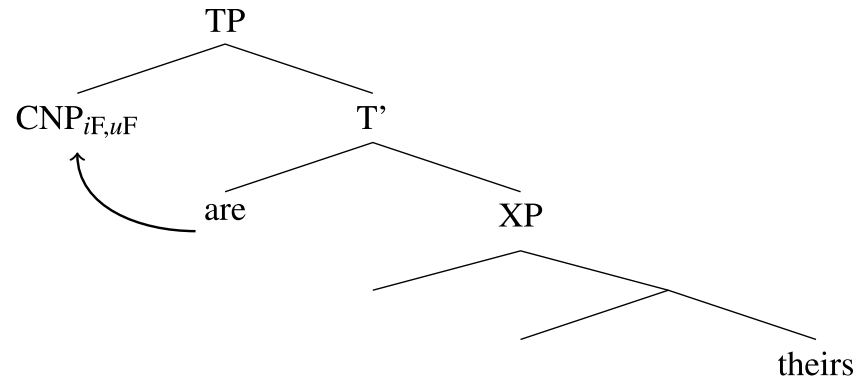

(48) Predicate Reading: the best committee $=$ predicate

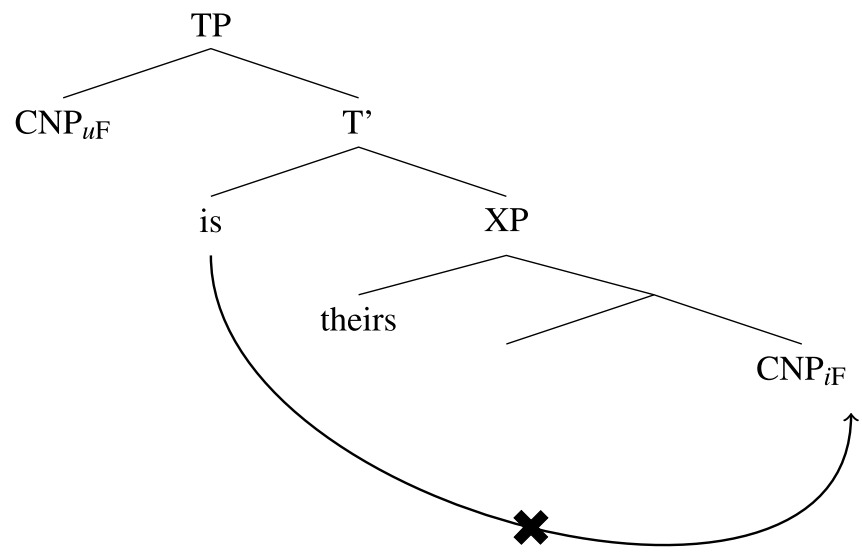

\subsubsection{Existential constructions}

For existential constructions, recall from Section 2.1 that the associate DP remains low in the structure, and does not raise to Spec, TP (contra Chomsky 1995, Elbourne 1999). This is the key part of the discussion, and nothing hinges on the structure beyond that. For concreteness, I loosely follow Hazout (2004) in assuming that the structure of existential constructions is the following. 
(49)

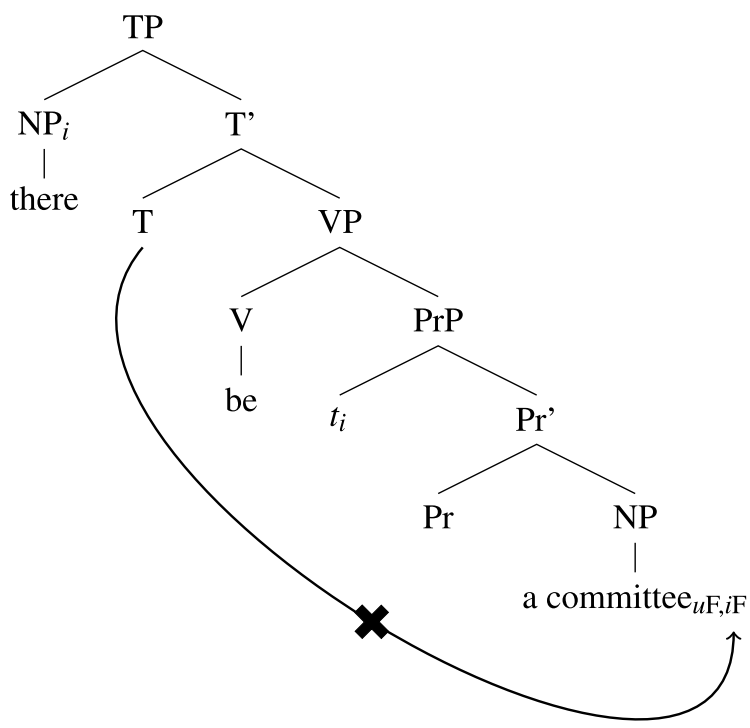

Again, we see that the $i$ Fs of the CNP are unable to control agreement, because they do not lie in the required configuration for AGREE-COPY to copy the value from them, as they do not lie in the required structural relationship where the $i$ Fs c-command the target of agreement. In contrast, $u$ Fs can value $\mathrm{T}$, since they are able to be accessed by AGREE-COPY in the PF branch, which is not limited to looking upwards in the structure.

\subsection{First conjunct agreement in English}

Before discussing how this analysis fares against other analyses of the restrictions on plural agreement, let us first consider an extension of this analysis to another phenomenon of English. ${ }^{23}$ It has been noted (Sobin 1997, Borsley 2009, Alexiadou, Anagnostopoulou \& Wurmbrand 2014) that when a conjoined phrase is the controller of agreement in a sentence, resolved agreement is preferred (whereby the features of the conjunction as a whole are used). However, first conjunct agreement is also found in English when the conjunction is in the associate position of existential sentences (the following examples are taken from Borsley 2009). ${ }^{24}$

[23] Thanks to Susi Wurmbrand, p.c. for pointing out the relevance of these data to me. Wurmbrand (2013) offers a similar account to the one presented here, though different in how agreement targets the first conjunct. In brief, Wurmbrand offers a linear explanation where if $i \mathrm{~F}$ agreement fails, T can agree with the linearly closest conjunct.

[24] Sobin (1997) shows that singular agreement is also possible in sentences of this type, but plural agreement is preferred overall. 
(50) A cat and a dog are in the garden.

(51) There is/*are a cat and a dog in the garden.

The fact that plural agreement is not allowed in sentences like (51) is backed up by the questionnaire experiment given in Sobin (1997), with the relevant results summarised in Table 2, notably sentence (f).

\begin{tabular}{llc}
\hline & Sentence & Score $^{25}$ \\
\hline (a) A cup and a napkin is on the table. & 2.22 \\
(b) A book and a pen's on the desk. & 2.69 \\
(c) A book and a pen are on the desk. & 3.31 \\
(d) There is a pen and a stamp on the desk. & 3.58 \\
(e) There's a book and a pen on the table. & 4.36 \\
(f) There are a book and a pen on the desk. & 0.81
\end{tabular}

Table 2

Results of Sobin (1997).

These data find a natural explanation in the current model of agreement. It has been commonly assumed in that conjunct phrases involve an asymmetric structure $\& \mathrm{P}$ such that the first conjunct c-commands the second (see, among others, Munn 1993, Benmamoun et al. 2009).

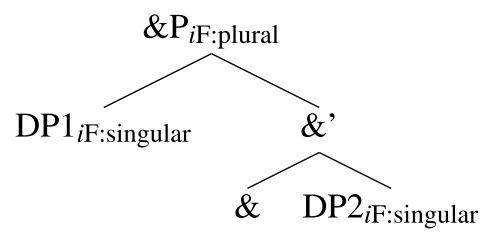

Although the \&P structure in (52) has been commonly assumed in Minimalism, it should be noted that it is not without controversy. For instance, Borsley (2005) offers a number of empirical and theoretical arguments against \&P. For the purpose of this analysis, \&P is orthogonal: what is required is a structure whereby the first conjunct is structurally more prominent than the second. This could be derived in various ways, such as the higher constituent being forced to move to that position to break an originally symmetric structure, as suggested in Chomsky (2013) (see also Moro 2000 and Ott 2012). I use the structure in (52) for concreteness, but the reader should bear in mind that the conclusion is not contingent on the \&P analysis of conjunction.

In addition to the features of the individual DP conjuncts, there are 'resolved' features on $\& \mathrm{P}$ that come from the conjuncts. This means that because there are

[25] Sobin's scale ranges from $0=$ completely unnatural to $5=$ completely natural. 
multiple instances of singular DPs in $\& \mathrm{P}, \& \mathrm{P}$ as a whole has plural number. This is shown below with the ability of $\& \mathrm{P}$ to license a plural anaphor.

(53) John and Mary saw themselves in the mirror.

I assume that, at least for English, \&P has no $u$ Fs of its own, but only $i$ Fs that come from a resolution of the conjuncts. Since $\& P$ has only $i$ Fs, we predict that it should only be able to be a controller of agreement when it lies above its target. When it lies beneath the verb, then the $i$ Fs will be unavailable. This prediction is borne out, as shown by the contrast between agreements in Table 2, in particular the contrast between sentences (c) and (f). When \&P is preverbal, in Spec, TP, then the $i$ Fs on $\& \mathrm{P}$ are able to be agreed with, which is possible, as shown in sentence (c) in Table 2. The structure is given below. We see that the $i$ Fs of $\& \mathrm{P}$ lie in the necessary upwards agreement configuration to show agreement, and so plural agreement is possible.

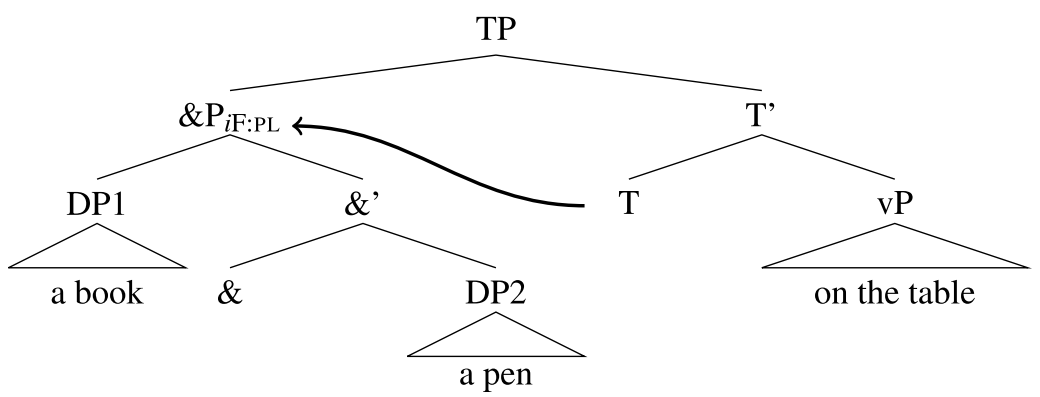

However, when \&P is the controller of agreement, but remains beneath $\mathrm{T}$, as in existential constructions, then the $i$ Fs should not be able to be targeted. In this case, I assume that $\mathrm{T}$ is able to look into \&P and undergo agreement with the highest DP. As the agreement looks downwards, then it will necessarily only target $u$ Fs given that the $i$ Fs are not able to be agreed with by a target that c-commands them. Since the first conjunct is singular, singular agreement is found here, as resolved agreement will only target $i$ Fs. Given that the associate of existential constructions does not c-command $\mathrm{T}$ at $\mathrm{LF}$, it follows from the assumptions here that we do not find resolved conjunct agreement in an existential construction. 
(55)

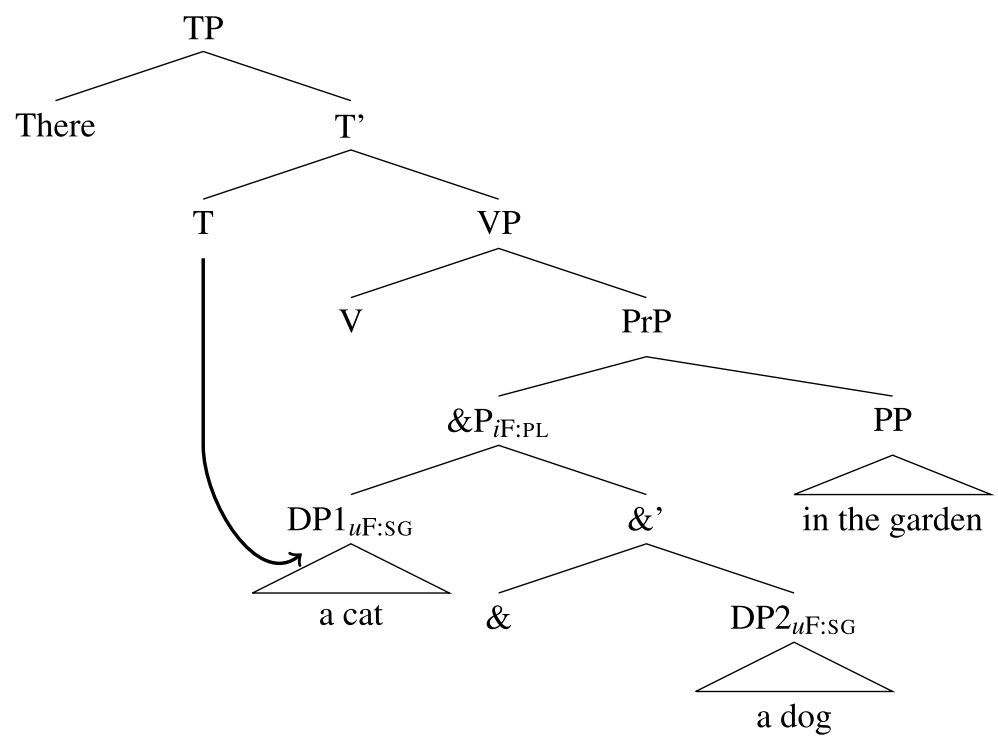

Note that if the first conjunct is plural, plural agreement is possible (56a). However, it is not sufficient to have some plural argument anywhere in the conjunct phrase to get plural agreement on the verb, as shown by the low acceptability of (56b) (the acceptibility scores are again taken from Sobin 1997, see footnote 25). The first conjunct is chosen as it is the closest DP to T.

(56) (a) There are some books and a pencil on the table.

(b) There are a cup and some plates on the table.

Thus, we find further support for the proposal here that $i \mathrm{~F}$ agreement is only possible when the $i$ Fs lie in a position above the target at LF.

\subsection{Interim summary}

In this section, I have outlined a theory of AGREE that is able to capture the distinctions between semantically motivated agreement and morphologically motivated agreement in English. The crucial aspect of the analysis is that semantic agreement reflects agreement of the target with the $i \mathrm{~F}$ of the controller. $i \mathrm{Fs}$ can only be targeted at the point of transfer, and I have proposed that if AGREECOPY occurs here, then it can only look upwards in the structure. Morphological agreement is different because AGREE-COPY is also able to target $u$ Fs postsyntactically, in which case AGREE-COPY can look either upwards or downwards in the structure. This model of AGREE also allows us to understand the first conjunct agreement effects in English, lending further support to the analysis. In the next section, I compare this approach with previous accounts of the phenomena, showing that the analysis given here covers more data than previous analyses, and is able to account more easily for mismatched agreement targets. 


\section{Previous approaches}

In this section, I contrast the proposal offered here against previous accounts of the same phenomena, and show that this account improves on the others by accounting for all of the facts under discussion, while other approaches can only account for a subset. Furthermore, I will show empirical problems for previous accounts.

Previous studies, to varying degrees, have covered the following constructionspecific restrictions on plural agreement: (i) the lack of plural agreement in expletive constructions, (ii) the inability of a CNP to reconstruct to a lower clause once it has triggered plural agreement and (iii) the subject/predicate reading asymmetry. In the following subsections, I will show that two classes of approaches have been taken. The first (espoused by den Dikken 2001 and Sauerland 2004a, b) claims that the differences between plural and singular agreement can be derived from a lexical difference between plural and singular agreeing CNPs. In essence, plural agreement is restricted because plural-agreeing CNPs contain an additional element that singular-agreeing CNPs lack, which in turn prevents them from appearing in certain environments. The second approach (Elbourne 1999) is largely in the same spirit as the approach I advocate for here, namely that the restrictions on plural agreement arise since the plural feature is not accessed due to its structural location. However, I note certain differences in assumptions between my approach and Elbourne's which have the effect that the approach given here captures a wider set of data.

\subsection{Plural agreeing CNPs are different}

Den Dikken (2001) and Sauerland (2004a, b) have argued for similar approaches, claiming that plural-agreeing CNPs are different from their singular-agreeing counterparts since they involve some extra element, which turns the regular singular CNP into a plural one. For den Dikken, this element is plurally specified pro, which combines in apposition with the CNP. For Sauerland, the plurality is obtained by the addition of a plural operator $\Gamma^{-1}$.

Den Dikken claims that pro causes the change to plurality in CNPs because it heads the resulting DP, and so the plurality of pro is obtained by the CNP as a whole. The pronominal nature of pro in turn causes the entire DP to take on the nature of being pronominal, and this causes the restrictions on plural agreement. Den Dikken proposes that the fact that one cannot get plural agreement in existential constructions derives from the fact that pronominals are not allowed in general to be the associate of existential sentences, a fact that is presumably related to the definiteness requirement on existential sentences in English and various other languages. Furthermore, den Dikken claims that the fact that the sentence in (57a) lacks the predicate reading falls out from plural pronouns being barred from predicate positions in general. If it is true that plural pronouns are prohibited from being in predicate position, then plural agreeing CNPs are barred 
from that position too, since pro forces them to become plural pronouns. Singular agreeing CNPs, lacking pro, are, however, allowed to be predicates: sentences with singular pronouns such as it as predicates are grammatical according to den Dikken, for instance you are it, and Coke is it.

(57) (a) The best committee is theirs. committee $=\boldsymbol{V}$ subject $/ \boldsymbol{V}$ predicate

(b) The best committee are theirs. committee $=\boldsymbol{V}$ subject $/ \boldsymbol{X}$ predicate

It is not clear that den Dikken's generalisation about plural pronouns not being able to be predicates is correct, however, since there do exist contexts in which they seem to be acceptable, though they are not widespread (see also Bošković 2002: footnote 35$):^{26}$

(58) (a) We have met the enemy and he is us.

(b) There are gods and we are them.

Sauerland (2004a, b) takes a similar approach to den Dikken, but instead of positing a plural pro that combines with the CNP that results in plurality, he instead proposes that the culprit is a plurality operator. This in turn makes the CNP a definite noun phrase, since the plurality operator $\Gamma^{-1}$ is of the semantic type $<\mathrm{e}, \mathrm{e}>$. Sauerland claims that this is the case even when CNPs combine with the indefinite article $a$; they may look like they are indefinite DPs but are in fact 'hidden definites', as Sauerland terms them. It is this that prevents pluralagreeing CNPs from appearing in the environments in which plural agreement is disallowed. As mentioned above, there is a well known definiteness restriction on existential sentences. Due to the fact that it is the plural operator on CNPs that allows them to control plural agreement, but in doing so causes the CNP to become definite, plural agreement triggered by CNPs is disallowed in existential sentences. Furthermore, Sauerland attributes the inability of plural-agreeing CNPs to reconstruct for scope to the claim that definite expressions cannot reconstruct for scope.

(59) (a) A northern team is likely to be in the final.

$\exists \gg$ likely / likely $\gg \exists$

(b) A northern team are likely to be in the final. $\exists \gg$ likely $/ *$ likely $\gg \exists$

However, both of the approaches fail to provide a complete account for the restrictions on plural agreement. Den Dikken's approach, whilst apparently able to capture the predicate/subject readings, is unable to account for the lack of scope reconstruction given that there is no clear reason why plural CNPs should be unable to reconstruct. Similarly, Sauerland's account struggles to account for the lack of predicate readings when there is plural agreement, as there is nothing wrong with having a definite description serve as a predicate.

[26] Thanks to Jonathan Bobaljik for pointing me towards the examples in (58). 
(60) (a) John is the man you need to talk to.

(b) Mount Everest is the highest peak on Earth.

Regardless of whether these approaches provide a full or incomplete picture of the data - additional assumptions may be able to help - a far more serious problem for this style of approach is that a single CNP can trigger both singular and plural agreement in the same sentence.

(61) (a) This committee are deciding the future of the project.

(b) * These committee are deciding the future of the project.

(c) The government has offered ?themselves / each other up for criticism.

(d) The government have offered ?themselves / each other up for criticism.

For both Sauerland and den Dikken, these sentences represent somewhat of a paradox. In both approaches, plural agreement necessarily arises when a CNP contains the additional plural element, otherwise the CNP is only able to control singular agreement. Thus, the fact that there can be mismatches between two targets of agreement is unexpected: a CNP should control either singular or plural agreement, but not both. Now, one could argue that (61a) is possible because demonstratives never show plural agreement, and so the presence of both singular agreement and plural agreement here arises because there is no other way that the sentence could be. However, in (61c), we have two targets of agreement that can each show both singular and plural agreement. Their cooccurence in the same sentence raises a serious concern.

Further concerning for this style of approach is that it does not appear to be true that the ability to control plural agreement prevents a CNP from appearing in a certain syntactic environment. We can see this with existential constructions. Consider the following (also noted in Elbourne 1999).

(62) There is a team starting to psych themselves up in that dressing room.

Here we see a CNP that is the associate in an existential construction. Predictably, the verbal agreement is singular. However, there is an anaphor in the adjunct clause that is plural. The problem that this causes for den Dikken and Sauerland is that the CNP is controlling plural agreement on the anaphor and is appearing in an existential construction. One or the other should not be allowed. Den Dikken does acknowledge the existence of such sentences (his footnote 19), and argues that this might simply be the result of a loose link between the subject and PRO in the adjunct, as is seen with partial control (Landau 2000). However, what is notable about (62) is that it involves an aspectual verb, start, which Landau (2000) claims prohibits partial control. Furthermore, den Dikken notes that the anaphor itself makes an analysis along the lines of partial control unlikely. Thus, without a mechanism to handle the existence of sentences like (62), these 
sentences remain genuinely problematic for the den Dikken/Sauerland style of approach.

\subsection{All CNPs are the same}

Sauerland and den Dikken's approaches were crucially based on the proposal that there is a fundamental difference between CNPs that control singular agreement and those that control plural agreement. This difference prevented plural-agreeing CNPs from appearing in certain syntactic environments.

Elbourne (1999) claims that all CNPs in British English have regular singular number, but they are also specified with a mereology feature, a special type of number feature that expresses collective plurality. ${ }^{27}$ In essence, CNPs are simultaneously singular and plural, since they contain both singular (regular) and plural (mereology) number features. This immediately allows us to account for the fact that both singular and plural agreement can be triggered by the same CNP, for instance in (61). Furthermore, there is no longer any problem with a CNP being able to antecede plural anaphors in existential constructions: CNPs are allowed to appear in existential constructions; it just appears to be the case that plural agreement is not possible on $\mathrm{T}$ (62).

In order to account for the contexts where plural agreement is not licensed, Elbourne resorts to a difference in the behaviour of the two number features: a regular number feature is able to raise to a position covertly, but mereology is not. That is, the only way to move mereology is to move it in the narrow syntax, before transfer to the interfaces. ${ }^{28}$ This works for Elbourne in the following way. In existential sentences, Elbourne adopts the analysis given in Chomsky (1995), where the associate in existential sentences remains low in the structure, before the features raise to Spec, TP covertly to check the agreement features on $\mathrm{T}$. For Elbourne, this rules out plural agreement in existential sentences because the plural feature is unable to join the other features in raising covertly. Singular agreement is fine because the regular number feature, singular on CNPs, faces no problems in raising covertly.

For the scope reconstruction cases, Elbourne appeals to Sauerland (1998), who gives an approach of PF movement whereby scope reconstruction effects are actually movement in the PF branch without a corresponding movement in the narrow syntax or on the LF branch of the grammar. This gives the effect of raising an element on the surface form of the sentence, but leaving it in the original place

[27] Elbourne only discusses British English, but his conclusions presumably hold for other dialects of English as well.

[28] It is worth stressing here that the [ $i \mathrm{~F}$ :plural] is not a simple rebranding of Elbourne's mereology. Here, I assume that the plural $i \mathrm{~F}$ is the semantic number value of a $\mathrm{CNP}$, and is not a type of number feature in addition to the regular number features that CNPs are endowed with. For this account, every feature has an $i \mathrm{~F}$ and a $u \mathrm{~F}$ value. CNPs are therefore not endowed with anything that other nouns are not; the difference is simply that their $i \mathrm{~F}$ has a different value from the $u \mathrm{~F}$, in place of the usual correspondence between the two. 
for the purposes of the semantics. The $\phi$-features of the element must still be checked, however, and this is done by covert feature movement. Consider the wide scope and narrow scope readings of the following sentence.

A person is likely to win the lottery. person $\gg$ likely/ likely $\gg$ person

In the narrow scope reading, where it is likely that some person will win the lottery, a person remains in the embedded clause, but in the PF branch, it moves into the matrix clause to occupy its surface position. This produces the mismatch where it is pronounced in the higher clause but interpreted in the lower clause. In the low position, its uninterpretable $\phi$-features must still be checked by spec-head agreement with T, following Chomsky (1995), and so they raise covertly to Spec, TP. In the wide scope reading, however, a person moves regularly in the narrow syntax into the higher clause. This takes with it all of its features, and so it is interpreted in the high position.

Returning to CNPs, Elbourne claims that the reason why plural agreement is disallowed is the assumption that the mereology feature cannot raise covertly. Plural agreement is not possible when there is a narrow scope reading of the CNP, since this requires movement of the CNP in the PF branch, followed by covert movement of the features to Spec, TP. With mereology unable to raise covertly, the plural feature on $\mathrm{T}$ is unable to be checked and so the derivation fails. The wide scope reading is fine since the CNP moves in narrow syntax taking all its features, including mereology, with it to the matrix clause. By contrast, singular agreement is fine when the CNP remains low in the syntax but moves into the high position in the PF branch; covert feature movement is not a problem for the singular number feature, and the derivation is able to successfully converge.

While Elbourne's approach does capture the facts from existential constructions and scope reconstruction, it does suffer from a number of shortcomings. First, it only offers a partial explanation of the facts; it is not clear how the asymmetry between subject readings and predicate readings can be resolved in this system. A further problem is that covert feature movement, or the lack of it with respect to mereology, in fact seems to be largely irrelevant in existential constructions. Den Dikken (1995) gives the following paradigm, showing that if features did move covertly to Spec, TP, then we would expect the anaphors in the following sentences to be licensed, contrary to fact.

(64) (a) Some applicants $i$ seem to each other S $_{i}$ to be eligible for the job.

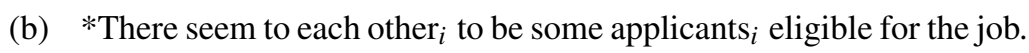

(c) Someone Seems to his $_{i}$ mother to be eligible for the job.

(d) *There seems to his ${ }_{i}$ mother to be someone $i$ eligible for the job.

These facts suggest that the associates in existential constructions remain low in the structure at all levels of representation, and never in fact raise to Spec, TP. Taking this to be true, then covert feature movement is irrelevant in existential sentences, and Elbourne loses the explanation here, and is left covering only the cases where scope reconstruction is disallowed with plural agreement. 


\subsection{Interim summary}

In this section, we have seen that previous approaches to explain the differences fail to offer a full account of the facts and give only partial explanations of the phenomenon, whereas, as shown in Section 3 above, the approach offered here accounts for all of the facts under a single theory. Furthermore, we have seen in this discussion that an approach where the difference between singular and plural agreement comes from a lexical difference between plural-agreeing CNPs and singular-agreeing CNPs struggles empirically with the ability of CNPs to license mismatches among multiple targets of agreement.

\section{Dialectal Variation}

Before concluding the paper, I turn to the issue of cross-dialectal variation. The approach that I take here differs from other formal accounts of the contrast between plural and singular agreement in that I explicitly make the connection between semantic agreement and plural agreement. On this point, I have been essentially following Corbett (1979 et seq.). Tying plural agreement to semantic agreement allows us to make two predictions, both of which are borne out once we look at dialectal variation in this realm. First, we do not expect to find a bifurcation of dialects of English into ones that do allow for plural agreement because of the addition of some extra element, and ones that do not. Rather, we expect to find that all dialects in principle allow for plural agreement, but at different frequencies. Second, plural agreement with CNPs ought to show characteristics that other instances of semantic agreement in other languages show. I turn first to the issue of how other dialects fare based on the corpus survey of Levin (2001), before looking at parallels with other instances of semantic agreement in Section 5.2.

\subsection{A continuum of registers (and dialects)}

Semantic agreement has been shown to be a process that involves gradience: it is not a completely free choice as to which agreement value a speaker chooses to utilise, but rather it is complicated by various considerations. Corbett (1983) describes the results of a large-scale study into gender agreement with profession nouns in Russian, such as the vrač examples in (27) above. Vrač 'doctor', recall, is morphologically masculine in Russian, controlling masculine agreement, but when the referent of the noun is a female, it can control feminine agreement. Corbett reports on a questionnaire study carried out by M.V. Panov (Panov 1968) and colleagues, where it was shown that feminine agreement with these hybrid profession nouns was used at different frequencies influenced by various factors. For instance, respondents who had maximally secondary education used feminine agreement more frequently than those with higher education. There were also effects of the region where the respondent lived, the occupation of the respondent, the gender of the respondent and the age of the respondent. For a complete overview, I refer the reader to the discussion in Corbett (1983). 
Such gradience in the use of plural agreement with CNPs has been noted by Levin (2001). Levin undertook a large corpus study into dialectal and lexical variation with CNPs in English, and I summarise some findings in the discussion here. Levin shows that within British English, the frequency of plural agreement rises when one switches from a written register to a spoken register. Levin looked at the rate of plural agreement with a CNP in The Independent, a broadsheet newspaper of the UK, and compared this with spoken data, from the British National Corpus. His results are repeated in Table 3. In fact, the same pattern holds in American English as well, as Levin shows (Table 4). Written data are drawn from The New York Times and spoken data from the Longman Corpus of Spoken American English (LSAC).

\begin{tabular}{|c|c|c|c|c|c|c|c|c|}
\hline & \multicolumn{4}{|c|}{ Independent } & \multicolumn{4}{|c|}{$\mathrm{BNC}$} \\
\hline & \multicolumn{2}{|c|}{ Singular } & \multicolumn{2}{|c|}{ Plural } & \multicolumn{2}{|c|}{ Singular } & \multicolumn{2}{|c|}{ Plural } \\
\hline & $\mathrm{N}$ & $\%$ & $\mathrm{~N}$ & $\%$ & $\mathrm{~N}$ & $\%$ & $\mathrm{~N}$ & $\%$ \\
\hline Verbs & 2260 & 77 & 683 & 23 & 1414 & 68 & 671 & 32 \\
\hline Relative pronouns & 417 & 59 & 293 & 41 & 115 & 42 & 162 & 58 \\
\hline Personal pronouns & 477 & 44 & 616 & 56 & 170 & 28 & 437 & 72 \\
\hline
\end{tabular}

Table 3

Plural versus singular agreement in written and spoken British English.

\begin{tabular}{|c|c|c|c|c|c|c|c|c|}
\hline & \multicolumn{4}{|c|}{ New York Times } & \multicolumn{4}{|c|}{$\overline{\text { LSAC }}$} \\
\hline & \multicolumn{2}{|c|}{ Singular } & \multicolumn{2}{|c|}{ Plural } & \multicolumn{2}{|c|}{ Singular } & \multicolumn{2}{|c|}{ Plural } \\
\hline & $\mathrm{N}$ & $\%$ & $\mathrm{~N}$ & $\%$ & $\mathrm{~N}$ & $\%$ & $\mathrm{~N}$ & $\%$ \\
\hline Verbs & 3149 & 97 & 84 & 3 & 476 & 91 & 48 & 9 \\
\hline Relative pronouns & 537 & 76 & 165 & 24 & 11 & 26 & 32 & 74 \\
\hline Personal pronouns & 941 & 68 & 442 & 32 & 14 & 6 & 225 & 94 \\
\hline
\end{tabular}

Table 4

Plural versus singular agreement in written and spoken American English.

These data are important for two reasons. First, they show that plural agreement shows the same pattern of gradience as semantic agreement has been shown to in Russian. Furthermore, they show that dialects of English do not bifurcate into dialects that do allow for plural agreement and those that do not. Rather, dialects of English form a continuum from dialects that are relatively happy to show plural agreement to dialects that are less permissive in this regard. This is further supported once we add in Australian English, where Levin shows that it lies somewhere between British English and American English in this respect (Table 5). Plural agreement has also been shown to be allowed in New Zealand English (Bauer 1988, Corbett 2000).

Finally, it is worth noting that there is lexical variation with how frequently different CNPs control plural agreement, as can be seen in Table 6. We can see 
THE SYNTAX OF SEMANTIC AGREEMENT IN ENGLISH

\begin{tabular}{|c|c|c|c|c|c|c|c|c|c|c|c|c|}
\hline & \multicolumn{4}{|c|}{$\mathrm{AmE}$} & \multicolumn{4}{|c|}{$\mathrm{BrE}$} & \multicolumn{4}{|c|}{ AusE } \\
\hline & \multicolumn{2}{|c|}{ Singular } & \multicolumn{2}{|c|}{ Plural } & \multicolumn{2}{|c|}{ Singular } & \multicolumn{2}{|c|}{ Plural } & \multicolumn{2}{|c|}{ Singular } & \multicolumn{2}{|c|}{ Plural } \\
\hline & $\mathrm{N}$ & $\%$ & $\mathrm{~N}$ & $\%$ & $\mathrm{~N}$ & $\%$ & $\mathrm{~N}$ & $\%$ & $\mathrm{~N}$ & $\%$ & $\mathrm{~N}$ & $\%$ \\
\hline Verbs & 3149 & 97 & 84 & 3 & 2260 & 77 & 683 & 23 & 1890 & 90 & 216 & 10 \\
\hline Rel pron. & 537 & 76 & 165 & 24 & 417 & 59 & 293 & 41 & 367 & 74 & 131 & 26 \\
\hline Per pron. & 941 & 68 & 442 & 32 & 477 & 44 & 616 & 56 & 457 & 61 & 289 & 39 \\
\hline
\end{tabular}

Table 5

Plural versus singular agreement in American, Australian and British English.

\begin{tabular}{cc}
\hline & The Independent \\
\hline $81-100 \%$ & association, audience \\
& $\begin{array}{c}\text { commission, committee } \\
\text { company, council } \\
\text { department, government } \\
\text { party, population }\end{array}$ \\
& army, band \\
& club, crew \\
& family, group \\
& minority, press \\
& public, team \\
& couple \\
& majority \\
& staff \\
\hline
\end{tabular}

Table 6

Rate of singular agreement with individual nouns in British English.

that a noun like staff occurs with singular agreement less than $40 \%$ of the time, whereas a noun like audience occurs with singular agreement over $81 \%$ of the time (these data are taken once more from Levin 2001). There are clearly other factors that influence whether a noun occurs with singular or plural agreement, which I do not have space to consider here.

\subsection{The Agreement Hierarchy}

Another property of semantic agreement is that certain elements are more likely to agree with the semantic specification of a noun rather than the morphological one. Corbett (1979) notes that the fact that auxiliaries in British English show semantically related agreement but demonstratives do not fits in with a wider pattern seen across languages which he terms the Agreement Hierarchy. In brief, Corbett argues (on the basis of data from a variety of languages) that there is a hierarchy of agreement targets with respect to whether they can show semantically motivated agreement, and not solely morphological agreement. For targets on the scale in (65), if some element is able to show semantic agreement, then all 
positions to the right on the scale will also be able to show semantic agreement. Conversely, if a position can show morphological (Corbett terms it syntactic) agreement, then all positions to the left will also be able to show morphological agreement.

(65) attributive - predicate - relative pronoun - personal pronoun $\leftarrow-$ morphological agreement semantic agreement $-\rightarrow$

Corbett's main interest with respect to English was that demonstratives show singular agreement and not plural agreement, and this follows from his hierarchy. Demonstratives are attributive elements, whereas auxiliaries are assumed to be predicate elements, and so the demonstrative versus auxiliary asymmetry with respect to plural agreement simply falls under a more general cross-linguistic pattern of semantic versus morphological agreement. British English (and English more generally), then, demonstrates the following cut-off point for where semantic agreement is possible. All elements to the right of the ' $\|$ ' symbol allow for semantic agreement, but not elements to the left.

$$
\begin{aligned}
& \text { attributive } \| \text { predicate }- \text { relative pronoun }- \text { personal pronoun } \\
& \leftarrow-- \text { morphological agreement }
\end{aligned}
$$

By following Corbett (1979) and treating plural agreement with CNPs as stemming from the semantics of the noun, the current proposal is consistent with a well established typological observation regarding semantic agreement.

\subsection{Plural agreement and distance}

A final property of semantic agreement is noted by Dowty \& Jacobson (1988), and refers to the tendency for semantic agreement to become more likely the further away from the controller the target is, in cases where semantic agreement diverges from morphological agreement:

... it has been observed that in grammatical-gender languages the gender of a pronoun in a discourse may indeed deviate from that of its antecedent in certain cases, especially if widely separated from it. The most common change is for the later pronouns to take on the natural gender (i.e. sex or animacy) of their referent, instead of the grammatical gender of the antecedent (Dowty \& Jacobson 1988:101).

Now, if plural agreement from CNPs reflects semantic agreement, the rate of plural agreement should increase the further away a target appears from its controller. This is borne out, as we see in the data from Levin (2001) in Table 7.

We can see from Table 7 that the rate of plural agreement with CNPs does increase the further the target gets away from the controller. For instance, in The Independent, the rate of plural agreement is at $49 \%$ when the controller and target are in the same clause, but rises to $55 \%$ when in a different clause. In the next sentence, the rate is $84 \%$ plural agreement, with $100 \%$ plural agreement in the next but one sentence, supporting the current analysis that plural agreement is semantically motivated. 


\subsection{Summary}

In this section, we have seen that one can make various parallels between plural agreement controlled by CNPs in English and semantic agreement in other languages, suggesting that they are one and the same phenomenon. Indeed, this connection is directly made in the approach I suggest here: plural agreement arises when the $i \mathrm{~F}$ of the CNP is the value that is used in agreement, and $i \mathrm{Fs}$ are the features interpreted by the semantics.

In fact, the data reviewed in this section provide further evidence for favouring this approach over the approaches of den Dikken (2001) and Sauerland (2004a, b). Recall that for the den Dikken/Sauerland style of approach, plural agreement could only arise when the CNP was endowed with an extra element, either a plural pro for den Dikken or a plural operator for Sauerland. Furthermore, when CNPs were endowed with these additional elements, they had to control plural agreement. Note, however, that a plural reading can be obtained with CNPs even when they control singular agreement, as shown below, where a singular-agreeing CNP successfully combines with gather, which requires a semantically plural subject. $^{29}$

(67) The government is gathering to debate the measure.

Given that the semantic plurality can apparently be obtained in the absence of the additional element, it casts serious doubt on the view that this additional element is responsible for plurality. Furthermore, the parallels to semantic agreement become mere coincidences, whereas here the properties shown by plural agreement reflect more general properties of semantic agreement that are known from elsewhere.

\section{Conclusions}

This paper has been concerned primarily with the behaviour of plural agreement when controlled by a CNP in English, and, crucially, why it is restricted in comparison to singular agreement. My aim in this paper has been to understand where these restrictions come from, given that plural and singular agreement superficially at least look interchangeable in simple sentences. Drawing on previous work in the literature, I have shown that plural agreement is restricted by structural considerations. However, it is of interest that these structural considerations hold at the level of LF. Furthermore, they only apply to plural agreement, not singular agreement, suggesting that semantically motivated agreement is restricted in ways that morphologically motivated agreement is not. In order to account for this behaviour, I have adopted, and modified, the model of AGREE in Arregi \& Nevins (2012), where AGREE is composed of AGREE-LinK and AGREECOPY. Semantically motivated agreement has different restrictions because it

[29] See footnote 10 above for why the fog is gathering is fine. 
requires AGREE-COPY to copy feature values from an $i \mathrm{~F}$, which is only possible upwards at the point of transfer. The values on $u$ Fs could also be copied in this manner; however, the values are further able to be copied during PF. Semantically motivated agreement and morphologically motivated agreement are thus formed by the same operation, AGREE; however, the differences between the two, at least in English, arise from the fact that AGREE has more derivational opportunities to access $u$ Fs than it does $i$ Fs.

\section{REFERENCES}

Alexiadou, Artemis, Elena Anagnostopoulou \& Susanne Wurmbrand Wurmbrand. 2014. Movement vs. long distance agree in raising: disappearing phases and feature valuation. In Hsin-Lun Huang, Ethan Poole \& Amanda Rysling (eds.), The North East Linguistic Society (NELS) 43, 1-12.

Alsina, Alex \& Boban Arsenijević. 2012. The two faces of agreement. Language 88, 369-379.

Arregi, Karlos \& Andrew Nevins. 2012. Morphotactics: Basque auxiliaries and the structure of spellout. Dordrecht: Springer.

Baker, Mark. 2008. The syntax of agreement and concord. Cambridge: Cambridge University Press.

Bauer, Laurie. 1988. Number agreement with collective nouns in New Zealand English. Australian Journal of Linguistics 8, 247-259.

Benmamoun, Elabbas, Archna Bhatia \& Maria Polinsky. 2009. Closest conjunct agreement in head final languages. Linguistic Variation Yearbook 9, 67-88.

Bhatt, Rajesh \& Martin Walkow. 2013. Locating agreement in grammar: an argument from conjunctions. Natural Language \& Linguistic Theory 31, 951-1013.

Bjorkman, Bronwyn \& Hedde Zeijlstra. 2015. Upward agree is superior. Ms.

Bobaljik, Jonathan D. 1995. Morphosyntax: the syntax of verbal inflection. Ph.D. dissertation, MIT.

Bobaljik, Jonathan D. 2002. A-chains at the PF-interface: copies and covert movement. Natural Language and Linguistic Theory 20, 197-267.

Bobaljik, Jonathan D. 2008. Where's phi? In Daniel Harbour, David Adger \& Susanna Béjar (eds.), Phi-theory: phi-features across modules and interfaces (Oxford Studies in Theoretical Linguistics), 295-328. Oxford: Oxford University Press.

Borsley, Robert D. 2005. Against ConjP. Lingua 115, 461-482.

Borsley, Robert D. 2009. On the superficiality of Welsh agreement. Natural Language \& Linguistic Theory 27, 225-265.

Bošković, Željko. 1997. The syntax of nonfinite complementation: an economy approach. Cambridge, MA: MIT Press.

Bošković, Željko. 2002. Clitics as nonbranching elements and the linear correspondence axiom. Linguistic Inquiry 33, 329-340.

Bošković, Željko. 2006. Case checking versus case assignment and the case of adverbial NPs. Linguistic Inquiry 37, 522-533.

Butt, Miriam. 2006. The dative-ergative connection. In O. Bonami \& P. C. Hofherr (eds.), Emprical issues in syntax and semantics, vol. 6, 69-92. New York: CNRS.

Champollion, Lucas. 2015. Distributivity, collectivity and cumulativity. http://ling.auf.net/lingbuzz/0 02133.

Chierchia, Gennaro. 1998. Plurality of mass nouns and the notion of "semantic parameter". In Susan Rothstein (ed.), Events and grammar, 53-103. Dordrecht: Kluwer.

Chomsky, Noam. 1995. The minimalist program. Cambridge, MA: MIT Press.

Chomsky, Noam. 2000. Minimalist inquiries. In Roger Martin, David Michaels \& Juan Uriagereka (eds.), Essays on minimalist syntax in honor of Howard Lasnik, 89-155. Cambridge, MA: MIT Press.

Chomsky, Noam. 2001. Derivation by phase. In Michael Kenstowicz (ed.), Ken Hale: a life in language, 1-52. Cambridge, MA: MIT Press.

Chomsky, Noam. 2013. Problems of projection. Lingua 130, 33-49.

Collins, Chris \& Paul Postal. 2012. Imposters: a study of pronominal agreement. Cambridge, MA: MIT Press.

Corbett, Greville. 1979. The agreement hierarchy. Journal of Linguistics 15, 203-225. 
Corbett, Greville. 1983. Hierarchies, targets and controllers: agreement patterns in Slavic. University Park, PA: Penn State Publishing.

Corbett, Greville. 2000. Number. Cambridge: Cambridge University Press.

den Dikken, Marcel. 1995. Binding, expletives and levels. Linguistic Inquiry 26, 347-354.

den Dikken, Marcel. 1998. Predicate inversion in DP. In Artemis Alexiadou \& Chris Wilder (eds.), Possessors, predicates and movement in the Determiner Phrase, 174-214. Amsterdam: John Benjamins.

den Dikken, Marcel. 2001. Pluringulars, pronouns and quirky agreement. The Linguistic Review 18, $19-41$.

den Dikken, Marcel. 2007. Relators and linkers. Cambridge, MA: MIT Press.

Dowty, David \& Pauline Jacobson. 1988. Agreement as a semantic phenomenon. ESCOL ' $88,95-108$. Columbus, OH: Ohio State University.

Elbourne, Paul. 1999. Some correlations between semantic plurality and quantifier scope. In Nancy Hall, Masako Hirotani \& Pius Tamanji (eds.), The North East Linguistic Society (NELS) 29, 81-92. Amherst, MA: GLSA.

Enger, Hans-Olav. 2004. Scandinavian pancake sentences as semantic agreement. Nordic Journal of Linguistics 27.1, 5-34.

Enger, Hans-Olav. 2013. Scandinavian pancake sentences revisited. Nordic Journal of Linguistics 36, 275-301.

Fox, Danny. 1999. Reconstruction, binding theory and the interpretation of chains. Linguistic Inquiry 30, 157-196.

Franks, Steven. 1994. Parametric properties of numeral phrases in Slavic. Natural Language \& Linguistic Theory 12, 597-674.

Franks, Steven. 1995. Parameters of Slavic morphosyntax. (Oxford Studies in Comparative Syntax), Oxford: Oxford University Press.

Gärtner, Hans-Martin. 2004. Scandinavian pancake sentences as semantic agreement. Nordic Journal of Linguistics 27.

Glushan, Zhanna. 2013. The role of animacy in Russian morphosyntax. Ph.D. dissertation, University of Connecticut.

Halle, Morris \& Alec Marantz. 1993. Distributed Morphology and the pieces of inflection. In Ken Hale \& Samuel Jay Keyser (eds.), The view from building 20, 111-176. Cambridge, MA: MIT Press.

Hazout, Ilan. 2004. The syntax of existential constructions. Linguistic Inquiry 35, 393-430.

Heycock, Caroline. 1995. Asymmetries in reconstruction. Linguistic Inquiry 26, 547-570.

Hicks, Glyn. 2009. The derivation of anaphoric relations. Amsterdam/Philiadelphia: John Benjamins.

Hristov, Bozhil. 2013. Defacing agreement. In Miriam Butt \& Tracy Holloway King (eds.), LFG13. Stanford, CA: CSLI Publications.

Huddleston, Rodney \& Geoffrey K. Pullum. 2002. The Cambridge grammar of the English language. Cambridge: Cambridge University Press.

Landau, Idan. 2000. Elements of control: structure and meaning in infintival constructions. (Studies in Natural Language and Linguistic Theory), Dordrecht: Kluwer.

Lasnik, Howard. 1995. Case and expletives revisited: on greed and other human failings. Linguistic Inquiry 26, 615-633.

Levin, Magnus. 2001. Agreement with collective nouns in English. (Lund Studies in English 103), Lund: Lund University Press.

Meechan, Marjory \& Michele Foley. 1994. On resolving disagreement: linguistic theory and variation - there's bridges. Linguistic Variation and Change 6, 63-85.

Moro, Andrea. 2000. Dynamic antisymmetry. Cambridge, MA: MIT Press.

Munn, Alan. 1993. Topics in the syntax and semantics of coordinate structures. Ph.D. dissertation, University of Maryland.

Munn, Alan. 1999. First conjunct agreement: against a clausal analysis. Linguistic Inquiry 30, 643-668.

Nevins, Andrew \& Pranav Anand. 2003. Some agreement matters. In Gina Garding \& Mimu Tsujimura (eds.), The West Coast Conference on Formal Linguistics (WCCFL) 22, 370-383. Somerville, MA: Cascadilla Proceedings Project.

Ott, Dennis. 2012. Local instability. (Linguistische Arbeiten 544), Berlin: de Gruyter.

Panov, M. V. 1968. Russkij jazyk i sovetskoe ob̌̌čestvo, III, Morfologija i sintaksis sovremennogo russkogo jazyka. Moscow: Nauka. 
Perlmutter, David M. 1972. A note on syntactic and semantic number in English. Linguistic Inquiry 3, 243-246.

Pesetsky, David. 1982. Paths and categories. Ph.D. dissertation, MIT, Cambridge, MA.

Pollard, Carl \& Ivan Sag. 1994. Head driven phrase structure grammar. Chicago, IL: The University of Chicago Press.

Preminger, Omer. 2011. Agreement as a fallible operation. Ph.D. dissertation, MIT, Cambridge, MA.

Preminger, Omer. 2013. That's not how you agree: a reply to Zeijlstra. The Linguistic Review 30, 491-500.

Preminger, Omer. 2015. Agreement and its failures. Cambridge, MA: MIT Press.

Preminger, Omer \& Maria Polinsky. 2015. Agreement and semantic concord: a spurious unification. Ms., University of Maryland.

Quirk, Randolph, Sidney Greenbaum, Geoffrey Leech \& Svartvik Svartvik. 1985. A comprehensive grammar of the English language. London: Longman.

Reuland, Eric. 2001. Primitives of binding. Linguistic Inquiry 32, 439-492.

Reuland, Eric. 2011. Anaphora and language design. Cambridge, MA: MIT Press.

Sauerland, Uli. 1998. Scope freezing. In Pius N. Tamanji \& Kiyomi Kusumoto (eds.), The North East Linguistic Society (NELS) 28, 169-182. Amherst, MA: GLSA.

Sauerland, Uli. 2004a. "A team," definitely. Snippets 9, 11-12.

Sauerland, Uli. 2004b. A comprehensive semantics for agreement. Ms., ZAS, Berlin.

Sauerland, Uli \& Paul Elbourne. 2002. Total reconstruction, PF-movement, and derivational order. Linguistic Inquiry 33, 283-319.

Smith, Peter W. 2015. Feature mismatches: consequences for syntax, morphology and semantics. Ph.D. dissertation, University of Connecticut, Storrs, CT.

Smith, Peter W. 2016. The agreement hierarchy and AGREE. Ms., Goethe-Universität, Frankfurt.

Sobin, Nicholas. 1997. Agreement, default rules, and grammatical viruses. Linguistic Inquiry 28, 318-343.

Sobin, Nicholas. 2004. Expletive constructions are not "lower right corner" movement constructions. Linguistic Inquiry 35, 503-508.

Svenonius, Peter. 2007. Interpreting uninterpretable features. Linguistic Analysis 33, 375-413.

Thoms, Gary. 2013. Anti-reconstruction, anti-agreement and the dynamics of A-movement. Presented at GLOW 36, Lund.

Wechsler, Stephen \& Larisa Zlatić. 2000. A theory of agreement and its application to Serbo-Croatian. Language 76, 799-832.

Wechsler, Stephen \& Larisa Zlatić. 2003. The many faces of agreement. Stanford, CA: CSLI.

Wechsler, Stephen \& Larisa Zlatić. 2012. The wrong two faces. Language 88, 380-387.

Witkós, Jacek. 2004. Raising expletives. Poznań studies in contemporary linguistics, 175-195.

Wurmbrand, Susanne. 2011. Reverse agree. Ms., University of Connecticut.

Wurmbrand, Susanne. 2012a. Agreement: looking up or down? Talk given at MIT, March 2012.

Wurmbrand, Susanne. 2012b. Parasitic participles in Germanic: evidence for the theory of verb clusters. Taal en Tongval 64, 129-156.

Wurmbrand, Susanne. 2013. Move, agree and phasehood in raising contructions - a typology. Lecture Series given at the University of São Paulo.

Zeijlstra, Hedde. 2004. Sentential negation and negative concord. Ph.D. dissertation, University of Amsterdam.

Zeijlstra, Hedde. 2012. There is only one way to agree. The Linguistic Review 29, 491-539.

\author{
Author's address: Goethe-Universität, Frankfurt, Norbert-Wollheim-Platz 1, 60629, \\ Frankfurt am Main, Germany \\ p.smith@em.uni-frankfurt.de
}

